\title{
Bericht über den 3. internationalen dermatologischen Congress, gehalten zu London vom 4.-8. August 1896.
}

\section{Charakter und Verlauf des Congresses.}

\author{
Ein Stimmungsbild
}

von Prof. A. Neisser.

Lieber Freund und sehr verehrter Herr Redacteur!

Sie wünschen von mir als Einleitung zu den Referaten einen Bericht über den allgemeinen Verlauf des Londoner Congresses, so zu sagen "ein Stimmungsbild“. Diesem Wunsche komme ich mit grössestem Vergnügen und mit aufrichtiger Freude nach, denn ich brauche mich nur an den Londoner Congress zu erinnem, um „in Stimmung“ zu lrommen und es freut mich eine Gelegenheit zu haben, um meinen freudigen und dankbaren Erinnerungen an den nach jeder Richtung hin gelungenen Congress Ausdruck geben zu köunen.

Dass wir von unseren englischen Collegen auf das Freundschaftlichste aufgenommen wurden, dass wir eine ebenso grossartige wie in behaglichster Form gebotene Gastfreundschaft genossen - das ist für Jeden, der unsere englischen Collegen kennt, viel au selbstverständlich, als dass es weiterer Worte darüber bedürfte. Hervorheben will ich hier nur den Empfangsabend, den auf Veranlassung des Comités der Lord Mayor den Congressmitgliedern bot und das in dem imposanten Festsaale des Cecil-Hôtels seitens der Engländer veranstaltete Banquett.

Nicht weniger befriedigt war sicherlich Jeder über das wissenschaftliche Ergebniss des Congresses und zwar nicht nur wegen des positiv Gebotenen, sondern auch wegen der für jeden späteren Congress gewonnenen Erfahrungen.

Der wissenschaftliche Erfolg war von vornherein gesichert durch die Anwesenheit einer so grossen Anzahl allseitig geschätzter und ver- 
ehrter Collegen aller Nationen. Ein Blick auf das Programm und auf die nachstehenden Referate wird genügen, um diese meine Behauptung zu rechtfertigen. Die Themata, die auf die Tagesordnung gesetzt worden waren, waren zumeist von actueller Bedeutung und die Fülle der Vorträge war derart, dass, wer sich Belehrung holen wollte, sie auf allen möglichen Gebieten unseres Faches reichlich finden konnte. Bedauerlich war nur die Trennung in zwei Sectionen für Dermatologie einer-, für Syphilidologie andererseits. Sicherlich hat der Zwiespalt, welche Sectionen man aufsuchen solle, Viele dazu geführt, keiner der beiden Sitzungen beizuwohnen. Freilich hielten sich die Meisten durch den Besuch der nicht sehr umfangreichen aber lehrreichen Ausstellung schadlos.

Dort fand man überall, namentlich vor der Ausstellung des Hospital St. Louis, kleinere und grössere Gruppen, die in lebhafter Discussion kleine Privatcongresse veranstalteten. Für mikroskopische Demonstrationen war in denkbar ausgiebigster Weise gesorgt und sicherlich ist noch nirgends eine solche Collection von Trichophyton-Culturen zusammen gewesen wie im Jahre 1896 in der Examination-Hall zu London. Ich wäre gewiss dafür, bei allen späteren Congressen den Mitgliedern für den Besuch solcher Ausstellungen viel mehr Zeit frei zu lassen; schade war es nur, dass auf diesem Congress die leidige Zweitheilung es war, welche dazu Gelegenheit bot.

Eine ganz neue Perspective für alle späteren Congresse wurde aber eröffnet durch die geradezu wunderbaren Krankendemonstrationen, die jeden Tag Früh und Nachmittag vor den Redesitzungen stattfanden. Man konnte den englischen Collegen, die seit Monaten diese Demonstrationen vorbereitet hatten, für diesen ebenso lehrreichen wie interessanten Theil des Programmes nicht dankbar genug sein. Ja man kann wohl sagen: Hätte die ganze Congressveranstaltung uur in diesen Demonstrationen bestanden, wobei natürlich dann dafür Sorge hätte getragen werden müssen, dass sich denselben öfentliche, allen Congressmitgliedern zugängliche Discussionen angeschlossen bätten, so wäre der Congress ein geradezu idealer zu nennen gewesen. Nicht in der öffentlichen Sitzung, wo über Prurigo viel geredet and viel gesehwiegen wurde - unser verehrter Freund Kaposi verzichtete aufs Wort! - wurde diese strittige internationale Frage gefördert, soudern der nächste Morgen, wo an so und so viel Fällen die ganze Unklarheit darüber, was jeder Einzelne unter Prurigo verstand zu Tage trat, brachte Klärung und Förderung. Und habe ich den verehrten Führer der französischen Schule, Besnier, richtig verstanden, so werden wir anf dem nächsten Pariser Congress weniger reden und reden bören, aber dafür mehr sehen als bisher und uns angesichts der Krankheitsfälle aussprechen und - wo die Ansichten anseinandergehen - uns hoffentlich einigen.

Der ausführliche Congressbericht wird Jeden, der nicht selbst diese Demonstrationen zu sehen Gelegenheit hatte, erkennen lassen, wie gerechtfertigt unser Aller Befriedigung über diese quantitativ wie qualitativ gleich grossartigen Veranstaltungen war. 
Zum Schluss will ich nur noch ein sehr erfreuliches Moment hervoiheben: die wahrhaft collegiale Art, in der alle Nationen mit einander verkehrten und die ibren äusseren Ausdruck in dem einstimmigen Beschlusse fand, den nächsten Congress im Jahre 1900 in Paris zu halten.

Wem aber verdanken wir diesen schönen Erfolg? Sie, verehrter Freund, wie jeder Andere, der die Veranstaltung von Congressen auf seinen Schultern gefühlt hat, weiss, dass Einer allein etwas derartiges nicht zu Stande bringt und dass nur durch das collegiale Zusammenarbeiten Vieler die Fülle von Arbeit, die die Vorbereitung eines solchen Congresses erfordert, bewältigt werden kann. So müsste ich denn auch thatsächlich eine lange Reihe von Namen aufzählen, wenn ich Jeden, der sich um den Erfolg verdient gemacht hat, einzeln nennen wollte. Aber wir alle wissen ebenso, dass alle die vielen Fäden der Mitarbeit in einem Centrum zusammenlaufen müssen, und so war es begreiflich, dass denjenigen Männern, welche als Präsident und als Generalsecretär an der Spitze standen, Hutchinson und Pringle, mit besonderer Begeisterung der Dank des Congresses votirt wurde. Mir persönlich ist es die liebste Erinnerung an diesen so schön gelungenen Londoner Congress, dass mir die Ehre zu Theil wurde, diesem Dank in Aller Namen öffentlich Ausdruck geben zu dürfen. Uns beiden aber, lieber Freund, wünsche ich, dass wenn wir wieder einmal einen Congress veranstalten, er so gelingen möge, wie der dritte internationale dermatologische Congress in London.

\title{
II. Referat über die Verhandlungen.
}

\author{
Von Dr. L. Elkind (London).
}

Die officielle Eröfnung des 3. internationalen DermatologenCongresses fand am Vormittage des 4. August im grossen Auditorium der Examination-Hall statt. Dr. J. J. Pringle, der Secretary General des Congresses entbietet zunächst den auswärtigen Collegen den formellen Willkommensgruss und weist in gewählter, prägnanter Form auf die Thätigkeit des Organisations-Comités hin. Hierauf verlas J. Hutchinson F.R.S., Präsident des Congresses, seine "Presidential-Adress". In der Einleitung begrüsste er ebenfalls die Mitglieder des Congresses, die von Nah und Fern herbeigeeilt sind, um an den wissenschaftlichen Verhandlungen activen Antheil zu nehmen. Keine Mühe, so fährt er fort, hạbe das Comité des Congresses gescheut, um den Empfang der auswärtigen Mitglieder und ihren weiteren A ufenthalt in London während der Congresszeit möglichst angenehm. zu gestalten. Der weitere Vortrag handelt, im Ganzen genommen, von den Beziehungen der Hauterkrankungen zu der gesammten Medicin. Die Entdeckung des Tuberkel-Bacillus hat das Verständniss und das that- 
sächliche Wissen in Bezug auf diejenigen Krankheiten, die als scrophulös bekannt waren, weit gefördert. Der wiederbolte Nachweis dieses eben genaunten Bacillus in lupus vulgaris, lupus necrogenicus und in anderen scrophulösen Neubildungen berechtigt uns zu der Annahme, dass diese Erkrankungen nur verschiedene Modificationen des tuberculösen Processes sind. Wenn auch hie und da in den eben erwähnten Firkrankungen der Tuberkelbacillus nicht nachgewiesen werden kann, so darf dies nicht als Beweis für seine völlige Abwesenheit genommen werden. Bleiben wir dabei, dass die ebengenannten Lupusformen tuberculöser Natur sind, so wollen wir jetzt dazu übergehen, aus den Erfahrungen und Beobachtungen, die wir an ihnen gemacht haben, allgemeine Gesetze in Bezug auf den tuberculösen Process zu ziehen.

I. Da ein tuberculöser Process für viele Jahre, ja selbst das ganze Leben hindurch, an einem umschriebenen Körpertheile beschränkt bleiben könne, erfahren wir täglich in derjenigen Form des Lupus, die als vulgaris solitarius bekannt ist.

II. Vom Lupus vulgaris multiplex lernen wir wiederum, dass selbst, wenn viele Frkrankungsherde an der Hauptoberfläche zugegen sind, jeder dieser Herde keine Tendenz zur Ausdehnung in das benachbarte Gewebe zeigt, und somit dem Gesetze des Beschräntkbleibens an einer circumscripten Stelle gehorcht. Freilich kommt eine Multiplicität der erkrankten Partien vor und in einem so ausgedehnten Grade, dass die ganze Hautfläche mit Lupusflecken besäet sein kann aber diese Eigenschaft des Lupus gehört ganz und gar lediglich der ersten Periode seiner Entwickelung an.

III. Obwohl wir nun mit Sicherheit wissen, dass der Lupus vulgaris durch Invasion von Tuberkelbacillen bedingt wird, so liegt uns doch ferne, auf Grund der biehergehörigen vielfach bestätigten Erfahrungen $z u$ befürchten, dass von einer lupösen Stelle aus eine weitere Infection z. B. der Lungen, Knochen etc. ausgehen müsste.

IV. Die Möglichkeit einer Latenzperiode bactericider Elemente im thierischen Organismus spricht sich wiederum am besten beim Lupus aus. Der Vortragende erwäbnt zwei Fälle aus seiner jüngsten Beobachtung, bei beiden bandelte es sich um Lupus der Xase, der lupöse Process heilte und sistirte vollständig für dreissig Jahre, um nach dieser Periode, im holen Alter der beiden Patienten, unter schweren. Erscheinungen wieder zum Ausbruch zu gelangen.

Auf den Lupus erythematosus übergehend, bemerkt H., dass hier noch eine grössere klinische Wahrscheinlichkeit, wie beim Lupus vulgaris, vorliege, ihn zu den tuberculösen Erkrankungen zu zählen. Hierher würde auch der von den alten Aerzten benannte Lupus sebaceus gehören. Der weitere Vortrag handelt von den Beziehungen der Hautaffectionen zu internen Erkrankungen, die Abhängigkeit verschiedener Hautläsionen in Bezug auf ihre ätiologische Bedeutung rom NervenSystem (Herpes zoster) etc. gestreift, eine bessere Classification der 
Nomenclatur in der Dermatologie an der Hand eigener und fremder Erfahrungen ausführlich besprochen und eingehend empfohlen.

Nachdem dieser mit vielem Beifall aufgenommene Vortrag zu Ende war, sprachen noch Kaposi und Besuier. Beide dankten den Mitgliedern des englischen Comités für die schönen Vorbereitungen zum Empfange der auswärtigen Mitglieder. Darauf folgte eine zweistündige Pause und um 3 Uhr Nachmittag wurden die Verbandlungen wieder aufgenommen und die Discussion über Prurigo füllte die für die NachmittagsSitzung bestimmten Stunden der beiden Sectionen.

Besnier (Paris). Strophulus und Lichen, die Willan zur Gruppe der papulösen Affectionen zählte, bilden gewisse Unterarten der Prurigo, die demnach besser als pruriginöse Erkrankungen bezeichnet werden können, wobei ein einheitlicher Begriff und Verständniss für den pathologischen Process, der diesen Affectionen zu Grunde liegt, gewonnen wird.

Pruritus ist nur ein Symptom, das in mannigfachen und unter sich ganz verschiedenen krankhaften Zuständen sich zeigt. Pruritus als eine Krankheit sui generis aufzufassen, oder ihm gar die Bedeutung eines Collectiv-Namens zu geben, hat keine Berechtigung.

"Prurigo Willani" und alle Formen des "Strophulus" und "Lichen" zählt der Redner zur Prurigo-Classe und bestreitet die Hebra'sche Auffassung, wonach dieselben in das Gebiet der Erythemata, Eczema und Urticarien gehören sollen.

Aetiologisch spielen in gewissen, wohl charakterisirten Prurigoformen die physiologischen Ernährungsvorgänge eine grosse Rolle, und bei solchen Individuen, die im Allgemeinen diathetische Eigenthümlichkeiten aufweisen, ist man berechtigt, von „Prurigo diatheticus" zu reden. Die neurologischen Forschungen auf dermatologischem Gebiete sind leider noch nicht so weit gediehen, um sie für die Formulirung und Beantw ortung der Frage, in wie weit eine Gefässneurose, Neurodermien und Neurodermitiden in der Prurigo eine Rolle spielen, zu verwerthen.

Abgesehen ron der essentiellen Ursache, die in der jeweiligen Prurigoform sicl geltend macht, ist die Wahrscheinlicbkeit nicht von der Hand zu weisèn, dass eine chemische Blutveränderung, und zwar höchst complicirter Natur, im Verlaufe der Krankheit sich ausbildet, und man würde demnach bei allen Prurigoarten. Toxidermien oder AutoToxidermien, bedingt durch ein toxisches Agens zu berüclsichtigen haben.

Es ist ferner Thatsache, dass in allen Prurigofällen die Hautläsionen durch den Pruritus bedingt werden. Dafür spricht der Umstand, dass nach Verschwinden und Zurückbildung der Papel der Pruritus unverändert fortbesteht, während das Umgekehrte - dass der Pruritus zurückgeht und die Papel sich noch erbält - bis jetzt noch nie beobachtet worden ist.

1. C. White (Boston U. S. A.) macht darauf aufmerksam, dass die von Hebra beschriebene, echte Prurigoform in Amerika ausserordentlich selten beobachtet wird. Während die wirklichen pathologischen Vorgänge 
bei der Prurigo noch nicht ganz aufgeklärt sind, so steht ätiologisch fest, dass schlechte Emährungsverhältnisse, mangelhafte Wohnungseinrichtungen, Vernachlässigung der Haut etc. etc. ihren Ausbruch begünstigen resp. herbeiführen.

J. F. Payne (London). Bei der echten Prurigo, meint der Redner, finden wir grobe anatomische Veränderungen der Haut, dabei besteht auch eine Herabsetzung des Perceptionsgefühles; letztere ist wohl die Folge eines chronisch-krankhaften Zustandes, in dem sich die sensiblen Nerven - central wie peripher - bei der Prurigo befinden.

Er difinirt Pruritus, der von Prurigo gänzlich verschieden ist, als eine functionelle Störung der Hautnerven. Die schwere Form der Prurigo (Hebra) ist in England eine seltene Erscheinung. Zur Prurigogruppe zählt er noch Prurigo mitis, simplex und Lichen urticatus.

Neisser (Breslau). I. Jede moderne Discussion über Prurigo muss ausgehen von dem von Hebra beschriebenen Krankheitsbilde: "Prurigo Hebra“. Sie ist die typische Form der Prurigo und is t charakterisirt: Jucken;

1. durch eine eigenthümliche Hautveränderung mit intensivem

2. durch eine typische Localisation;

3. durch einen eigenartigen Verlauf. Beginn der Erkrankung in früher Jugend, Dauer der Erkrankung viele Jahre, meist das ganze Leben hindurch.

II. Die Hautveränderung bei typischer Prurigo besteht in einer a) diffus teigig ödematösen Durchtränkung des gesammten Bindegewebes, b) in kleinen ganz oberflächlichen Efflorescenzen minimalster Urticariaeruptionen, zu denen sich kleinste Vesiculationen in der obersten Epithelschichte gesellen.

Alle Pustulationen, Excoriationen, Irnpetigoformen, Hornsehichtverdichtungen, alle Lichenificationen, Eczematisationen, sowie die Drüsenschwellungen, Verhärtungen der Haut sind artificielle und secundäre Erscheinungen. Die Verdickung des Bindegewebes kommt nicht durch ein zellig, entzündliches Infiltrat, sondern durch eine transudative ödematöse, urticarielle Durchtränkung zu Stande. Der vasomotorischtransudative Vorgang ist analog dem der Urticaria und besteht in einer durch Reizung vasodilatorischer Nerven bedingten arteriellen Hyperämie und in einer vermehrten Lymphproduction resp. Lymphsecretion.

III. Zur Erklärung der Thatsache, dass die Localisation der typischen Prurigo Hebrae an den Extremitäten der Vertheilung der Haare entspricht, kann die besonders reichliche Gefässversorgung der Haarwurzel herangezogen werden. Vielleicht spielt auch eine Contraction der arrectores mit.

IV. Die sogenannten "Eczeme" des Gesichts mit ihrer Abgrenzung anf die Seitentheile desselben hält N. auch für Prurigoeruptionen und die meist bei Prurigo "Hebrae" vorhandene Trockenheit der Haut- 
fläche, die Tỉhatsache, dass durch alle erweichenden Methoden (Bäder, Salben, Seifen, Schwitzen) in kurzer Zeit erhebliche Besserung erzielt, und die objectiven Erscheinungen zum Vexschwinden gebracht werden können, deute darauf hin, dass vielleicht auch Functionsstörungen der Drüsen, speciell der Schweissdrüsen am Krankheitsbilde betheiligt sind.

V. Knötchenbildung und Juckreiz sind gleichzeitige und untrennbare Erscheinungen. Das Kratzen, die Folge des Juckreizes, verstärkt die örtlichen Vorgänge, ruft vielleicht auch neue Eruptionen in der zur urticariellen Reaction veranlagten Haut hervor.

VI. Zur Prurigo darf man als atypische Formen (neben die typische Form Hebrae) nur diejenigen Hautleiden stellen, bei denen die oben geschilderte Art der Efflorescenzenbildung vorhanden ist, während die Localisation, der Gesammtverlauf und die Efflorescenzenbildung gewisse Modificationen aufweisen können. - Als atypische Prurigoformen fasst N. daher auf:

c) Prurigoerkrankungen, die nur durch Beginn im späteren Kindesoder Jugendalter sich von typischer Hebra'scher Prurigo unterscheiden; b) die acute temporäre Form (Brocq, Tommasoli, Mibelli), die freilich durch Jahre lang anhaltende Recidive auch einen chronischen Verlauf nehmen kann. (Diese Form entspricht dem "Lichen acutus" Vidal); c) einzelne Fälle der von $\mathrm{Vida}$ lals Lichen polymorphe mitis und ferox, von Besnier als Prurigo diathésique bezeichneten Gruppen. In ihrer Totalität freilich vermag der Redner nicht diese Gruppen als Prurigo aufzufassen, denn in, ihnen finden sich Krankheitsformen vereinigt:

1. echte Hebra'sche Prurigo mit stark ausgeprägter Lichenisation und Eczematisation.

2. atypische Prurigo mit starker Lichenisation und Eczematisation von der Wiener Schule als "Eczema prurigonosum" beschrieben;

3. Fälle mit (aus irgend einer Ursache entstandener) Eczematisation und Lichenisation, die aber nichts specifisch-pruriginöses (ausser dem Jucken) aufweisen.

Wie verhält sich unsere eben dargelegte Auffassung zu der der Wiener und Pariser Schule?

1. Wir anerkennen eine atypische Prurigoform neben der typischen Form Hebra's (mit der frauzösischen Schule, mit Tommasoli gegen Kaposi).

2. Wir stellen die typische Prurigo Hebrae und die atypischen Formen nebeneinander als Schwestern derselben Familie hin, während die französischen Autoren auch die typische Prurigo Hebra e nur als einen sehr hohen (besonders durch Lichenification und Eczematisation zu Stande kommenden). Grad der anderen Prurigoformen auffassen.

Während die französischen Autoren geneigt sind, jeden Fall mit hochgradiger und verbreiteter Lichenification und Eezematisation als Prurigo zu bezeichnen, nennt $N$. den Fall Prurigo (typica oder atypica) nur dann, wenn in bestimmter Localisation angeordnete specifisch-pruxiginöse Eftlorescenzen den Ausgangspunkt bilden. Für uns ist Lichenisation und 
Eczematisation stets etwas nebensächliches; sie können bei Prurigo als secundäre Erscheinungen stark oder schwach ausgeprägt vorhanden sein. Die französischen Autoren fassen den Prurigo-Begriff zu weit, die Wienerschule zu eng. Letztere thut Unrecht, wenn sie beim Eczema prurigonosum z. B. das Hauptgewicht auf die eczematösen Eruptionen statt auf die pruriginöse Grundlage legt, oder als „Eczema papulosum" bezeichnet, was vollkommen der typisch-pruriginösen Eruptionsform entspricht.

VII. Zur Prurigo-Gruppe wird auch gezählt die bei Kindern als Strophulus beschriebene Affection (Urticaria papulosa, Lichen urticatus).

Wie unterscheidet sich der Strophulus von der Prurigo?

1. Durch eine ganz andere Localisation. 2. Durch ein ganz regelmässiges Abheilen. 3. Durch das absolute Fehlen jeder Mitbetheiligung der tieferen bindegewebigen Hautschichten.

Unter allen Umständen aber, mag man den Strophulus in nähere oder weitere Beziehung zur Prurigo bringen, gehört diese Erkrankung, wie überhaupt die Urticaria zusammen mit Prurigo zu einer Classe der vasomotorischen Dermatoneurosen.

VIII. Vollkommen zu trennen von der Prurigo und den pruriginösen Formen sind die als Lichen chronicus simplex, Pseudolichen, primäre Lichenification bezeichneten Eruptionen.

In reiner Form ist diese Dermatose eine theils in papulöser, theils in flächenhafter Form aufiretende oberflächliche Hautentzündung (mit geringer Transudationstendenz und unbedeutender Epithelalteration), meist verbunden mit einem an Intensität sehr wechselnden Juckreiz und verstärkt durch andauernde mechanische Reibung. Es kann auch ein chronischer Juckreiz resp. durch ihn hervorgerufenes Kratzen Ursache der Dermatose sein. Je nach der Stärke und Dauer der mechanischen Irritation, die sich mit dem im Laufe der Erkrankung immer stärker werdenden Juckreiz steigert, wird diese anfangs trockene squamöse, lichenificirte Dermatitis durch Steigerung der entzündliohen Erscheinungen und Zunabme der Epithelalteration zu einer eczematösen. Das Jucken, meist stark ausgesprochen, kann unter Umständen, wie es beim Lichen ruber beobachtet wird, fehien; jedenfalls, meint $\mathrm{N}$, ist es unerwiesen, dass das Jucken das Primäre sei.

XI. Es gibt Mischformen und Uebergänge aller der oben genannten Typen, sowie "neue Formen", deren Systematisirung im einzelnen Falle schwierig und strittig, zur Zeit sogar ganz unmöglich ist. (S. These XIV. aus: "Ueber den gegenwärtigen Stand der Lichenfrage", Archiv XXVIII. 1894.)

Als Grundlage für die Systematisirung solcher Eruptionen ist festzustellen: 1. Welche spielt im Auftreten und Ablauf der Krankheit, wie im klinischen Bilde überhaupt der Juckreiz (Sensibilitäts-Neurose?) 2. Ist eine urticariaartige vasomotorische Transsudation charakteristisch für die Art, Form and Schnelligkeit des Auftretens, sowohl der Einzeleftiorescenzen wie der gesammten Hautveränderung? 3. Sind entzünd- 
liche Processe vorhanden und - wenn das der Fall ist - sind sie wesentlich und primär für die Entwicklung wie für den Ablauf der Einzeleffiorescenzen, oder sind die im Verlauf der Hautaffection eventuell sich einstellenden entzündlichen Vorgänge secundär, namentlich in Folge des Kratzens aufgetreten?

$\mathrm{X}$. Es ist nicht richtig, die Prurigo typica Hebra als eine unheilbare Krankheit zu bezeichnen. Bei energischer, lange fortgesetzter Hautpflege gelangen die milderen Formen der Kinder meist zur Heilung.

XI. Meist sind die Prurigo-Kranken schwache, im Wachsthum anffallend zurückgebliebene Menschen, doch hält N. den schlechten Status nicht für die Ursache der Prurigo, sondern er ist umgekehrt die Folge der Schlaflosigkeit etc. oder die Folge der allgemeinen schlechten Lebensverhältnisse. Die Tuberculose ist weder die Ursache noch die Folge der Prurigo und ist nur deshalb häufig bei Pruriginösen zu finden, weil beide Krankheiten in den schlecht situirten Volksclassen sich häufiger zeigen.

Professor Janovsky (Prag), ist für die Beibehaltung des Typus Hebra auf Grund von 600 genau beobachteten Fällen. Alle Fälle datirten aus der frühesten Kindheit: in den meisten Fällen zeigten sich bestimmte Prodrome zu Anfang. Von den beobachteten Fällen heilten 7 . Der Pruritus ging nicht voran, entwickelte sich erst mit den ersten Knötchen. Was die von Besnier beschriebene Toxidermie anbelangt, so wurde dieselbe in 2 genan in Bezug auf den Stoffwechsel untersuchten Fällen nicht nachgewiesen, Die Resultate der Harn-Untersuchung (Jndol, Scatol, gepaarte Schwefelsäure, Harnstoffbestimmungen) waren negativ. Ebenso enthielt der Urin keine toxischen Substanzen, weder liessen sich darin Eosinzellen nachweisen noch irgend andere pathologisch-chemische Veränderungen.

Jadassohn (Breslau). 1. Nicht bloss mit allen möglichen, indifferenten Behandlungsmethoden, sondern auch ohne alle Behandlung werden selbst schwerere Prurigofälle im Hospital geheilt; d. h. die Hauterscheinungen schwinden spontan, recidiviren aber - ebenso wie nach localer Behandlung meist sehr schnell. Diese Thatsache scheint in der That zu beweisen, dass Ernährungs- oder andere äussere Verhältnisse eine grosse Bedeutung für die Aetiologie der Prurigo haben.

2. Untersuchungen von Dr. Pinner über eosinophile Zellen beweisen, dass diese in der That häufig, wenn nicht regelmässig, im Blut vermehrt sind. In pruriginöser Haut sind sie häufig in grosser Zahl vorhanden, doch ist weder hier noch im Blut ihre Frequenz proportional der Schwere oder dem Stadium der Erkrankung. Fine specifische Bedeutung also haben die eosinophilen Zellen bei der Prurigo wohl ebensowenig wie bei der Dermatitis herpetiformis.

3. Kin Fall von typischem Lichen chronicus circumscriptus (Vidal) mit Localisation am Nacken aus J.'s Beobachtung verlief obne jedes Jucken und wies nie Kratzeffecte auf. Solche Beobachtungen beweisen wohl, dass diese sehr charalsteristische Hauterkrankung, in welcher das 
Jucken fast immer eine das Bild beherrschende Rolle spielt, ganz wie der Lichen ruber in seltenen Fällen auch ohne Jucken vorkommt, dass also das letztere nicht das eigentlich Primäre sein kann.

\section{Mittwoch, 5. August.}

A. Cooper. Discussion über syphilitisehe Reinfection.

Da Fournier (Paris) abwesend war, so leiteten A. Cooper und E. Cotterell die Discussion über dieses Thema ein. Zunächst wollen die Vortragenden beweisen, dass obzwar die erste Infection mit syphilitischem Virus in dem inficirten Idividuum die Immunität gegen weitere Infection mit demselben Virus herstellt, so ist doch eine Reinfection der Syphilis, wenn auch ein seltenes Ereigniss, doch keineswegs ausgeschlossen. Dasselbe gilt von der sogenannten congenitalen Syphiljs, auch hier ist das Individuum vor einer weiteren Infection geschützt, aber auch hier wiederum zeigen sich Abweichungen von der eben erwähnten Regel. Grosse Vorsicht, meinen die Autoren, müsse in Bezug auf diejenigen Fälle geübt werden, die gewöhnlich als syphilitische Manifestationen secundärer Natur aufgefasst werden. Aus dem Umstand, dass eine vernünftige und regelrecht ausgeführte $\mathrm{Hg}$. Behandlung die Syphilis vollständig zum Heilen bringt, wollen noch die Autoren einen Beweis für die Möglichkeit der Reinfection zieben. Ricord soll die Möglichkeit der Reinfection nicht in Abrede gestellt haben. Einer der Redner (Cotterell) hat viele Fälle gesammelt, in denen eine wirkliche Reinfection angeblich nachgewiesen war. Nicht durch bestimmte Symptome, wohl aber durch ein streng localisirtes, hartes Geschwür ist die Reinfection charalkterisirt. Dass die Syphilis, wie er nebenbei bemerkt, das Zustandekommen anderer Infectionen nicht ausschliesst, beweist der von Hutehinson berichtete Fall, in dem Syphilis und Variola zu gleicher Zeit zum Ausbruche gelangten.

H. Fitz Gibbon (Dublin). Wie alle anderen Erkrankungen, die von grossen Exanthemen begleitet sind, ein specifisches Fieber erzengen, so lässt sich auch dasselbe von der Syphilis sagen, die, wenn keine Complicationen sich einstellen, einen zeitlich wohl begrenzten Verlauf beobachtet. Gleich andern Infectionskrankheiten, wie z. B. Variola, Kuhpocken etc. folgt auf das erste Stadium eine Periode, während welcher das inficirte Individurum einer Reinfection unzugänglich ist, und während welcher wiederum diejenigen Elemente des Körpers, die das syphilitische Virus, so zu sagen, aufnahmen, entweder ganz zu Grunde gehen oder grosse Widerstandsfähigkeit gewinnen. Wie alle anderen exanthematischen Erkrankungeu der Rückbildung vollständig fähig sind, so gilt dasselbe von der Syðhilis, nur ist hier der Process langwieriger, zu Stillständen und Wiederausbrüchen geneigt. Bei der grösseren Majorität der syphilitisch inficirten Inđividuen ist vollständige Heilung die Regel, dafür liegen zahlreiche Erfahrungen und Beweise vor. Man kann im allgemeinen sagen, dass nach einer fünfjährigen Periode die Krankheit vollständig ausheilt und dass auch nach dieser Zeit die Immunität sich verlieren kann. Die Reinfection, meint F., 
erfolge eher auf dem Wege der Einimpfung syphilitischen Virus unreinen. septischen Ursprunges, als bei gewöhnlichem Contact mit reinem syphiliti . schen Gifte. Dafür sprechen die gesammelten Erfabrungen, dass wenn eine secundäre Infection mit dem in Rede stehenden Virus zu Stande kommt, die Krankheit einen viel schwierigeren Verlauf, als es sonst der Fall ist, annimmt. Hierbei erwähnt der Vortragende einen Fall aus seiner eigenen Beobachtung und die von Taylor aus N.-Y. beschriebenen Fälle, von denen zwei, wie Taylor sich ausdrückte, ,ganz schnell mit dem Tode endeten".

Wickham (Paris) bezieht sich auf Fournier, der noch nie bis jetzt in seiner langjährigen und ausgedehnten Praxis einen unzweifelhaften Fall von Reinfection beobachtet hatte, Namentlich lässt sich das am besten an Kranken vom "Hôpital St. Louis" verfolgen. An der Abtheilung, die unter Fournier's Leitung steht, wird schon seit über 20 Jahren in der Weise verfahren, dass jeder syphilitische Kranke in eine bestimmte Rubrik der Krankenbücher eingetragen und jedesmal bei seiner Repräsentation von Neuem Notizen gemacht werden. Diese Krankengeschichten, die also als zuverlässig erachtet werden dürfen, weisen keinen einzigen Fall von Reinfection auf.

Von den weiteren Rednern, die an der Discussion sich betheiligten, sei noch erwähnt Petrini de Galałz (Bucharest), der đie Möglichkeit der Reinfection bezweifelt. Drysdale (London) bemerkt, dass er einen unzweifelhaften Fall von Reinfection noch nicht beobachtet habe. Wickham (Paris) bezweifelt ebenfalls die Möglichkeit der Reinfection. Ogilvie gibt die Möglichkeit der Reinfection zu und bezieht sich auf einen Fall, der sich 1876 syphilitisch inficirte und nach einer Periode von 15 Jahren, nämlich 1891, sich von Neuem mit Syphilis inficirte und die Erscheinungen eines primären Affectes bot. Mehrere der von Hutchinson vergangenes Jahr beschriebenen Fälle scheinen unzweifelhaft für die Möglichkeit dex Reinfection zu sprechen: Prof. Pellizzari schliesst sich den Ausführungen des Vorredners an und meint, dass das Vorkommen von Reinfection nicht bezweifelt werden kann. Dr. Vermois erwähnt eine eigene und die von Trousseau gemachte Beobachtung, dass bei einer und derseiben Person Variola zum dritten Mal auftrat. Zambaco Pasha meint, da Variola zum ofteren dasselbe Individuum befallen kann, so darf daraus eine Analogie auf andere Krankheiten gezogen werden, doch liesse sich keineswegs daraus mit Sicherheit ein Beweis für die Reinfection ziehen, viel mehr sprechen alle andern. Erfahrungen dagegen. Güntz (Dresden) citirt die Hebra'sche Bemerkung, dass $8 \%$ von Variola-Kranken diese Infection zweimal durchmachen.

Hutehinson verweist darauf, dass es sich vornehmlich um die Frage dreht, ob Reinfection überhaupt möglich ist, nicht etwa ob ein Individuum zwei vollständige Attaquen von Syphilis exfahren könne Hier müssen die Erfahrungen entscheiden. H. selbst hat während seiner vierzigjährigen Praxis viele hierhergehörige unzweifelhafte Fälle gesehen. Man müsse einen Unterschied zwischen Spital- und Privat-Praxis machen. 
Patienten aus der Privat-Praxis lassen sich sehr lange hindurch verfolgen und beobachten, während es bei Spital-Patienten nicht der Fall ist. Er kritisirtPetrini de Galatz' Seepticismus und meint, dass die Fälle von Fitz, Gibbon und Ogilvie viel Beweisendes für sich haben.

Grünfeld (Wien) meint, dass so lange als eine secundäre Infection auf dem Wege des Experimentes nicht nachgewiesen worden ist, auch die Möglichkeit einer Reinfection bezweifelt werden müsse.

Am Nachmittag des zweiten Verhandlungstages wurden

\section{in der Seclion für Syphilis}

folgende Vorträge gehalten:

Zambaco-Pascha (Constantinopel) hielt seinen angekündigten Vortrag (Leprosy and Syphilis), der eine interessante Diseussion hervorrief: Geschichtlich sucht der Redner nachzuweisen, dass Syphilis bereits zu Zeiten Christoph Columbus bekannt war. Er weist ferner auf die Confusion hin, die in früheren Zeiten zwischen Syphilis und Lepra, die ununterbrochen mit einander verwechselt worden sind, existirte. Welches Resultat hatte die Erkenntniss, dass diese Krankheiten in keinem Zusammenhang mit einander stehen? Sobald der Untersehied zwischen diesen beiden Affectionen ermittelt worden ist, wurde den syphilitischen Kranken freier Lauf gelassen, während die armen, an Lepra leidenden Patienten so zu sagen eingekerkert worden sind. Auf die Frage, ob Lepra contagiös ist, übergehend, drückt sich Redner ganz entschieden gegen die Annahme einer Contagiosität der Lepra aus. Er selber, so fügt der Redner hinzu, hat hunderte von Lepra-Kranken beobachtet und nie die contagiöse Natur feststellen können. In Pariser Spitälern wurden Lepra-Kranke mit anderen Kranken in einem und demselben Raum behandelt, und nie ist bis jetzt noch eine Erfahrung von da ausgegangen, dass Lepra übertragen wurde. Ja, und noch mehr, einen innigeren Contact, als den zwischen Mann und Weib könne man sich doch nicht vorstellen, und er suchte vergebens nach Daten, wo ein leprakranker Ehegatte sein Weib mit dieser Krankheit ansteckte. Die Bacillenlehre bei der Lepra ist sehr schön, hat aber nur theoretischen Wertb.

Als zweiten Redner über diesen Gegenstand haben wir Prof. Campana (Rom) zu nennen. Er hält vor Allem fest an der bacillären Natur der Lepra. Die Bacillen, also die wirklichen Krankbeitserreger der in Rede stehenden Affection, halten sich vornehmlich in leprös-erkranktem. Gewebe auf. Sie sind Anaeroben, und die Gesetze ihrer Uebertragung richten. sich nach diesem ihren biologischen Zustande. Die mikroskopische Ermittlung dieser Bacillen erleichtert erstlich die Diagnose, und unterscheidet. sie welche Formen sie auch annnehme, von der Syphilis. Bei der Behandlung müsse die Lepra zuerst als solche in Angriff genommen werden, unbekümmert um septische oder andere Processe, die sich ihr zugesellen. Die Errichtung von speciellen Spitälern für solche Kranke hat sich als ein Segen erwiesen. 
v. Petersen (Petersburg) leugnet die autochthone Entstehung der Lepra und nimmt mit Campana die contagiöse Natur derselben an. Seine weiteren Ausführungen über diesen Gegenstand findet der Leser in der Sonnabend-Verhandlung des Congresses.

Drysdale (London) bestreitet entschieden die negative Haltung $Z a m b a c o$ Pascha's in Bezug auf die Contagiösität der Lepra und bemerkt, dass in der Praxis eine grosse Gefahr darin liege, Lepra-Kranke als uncontagiös hinzustellen. Er erwähnt ein ganz interessantes Beispiel. In London hat sich eine Zeit lang die Ansicht erhalten, dass Phthisis nicht contagiös sei, unangenehme Erfahrungen jedoch haben diese Theorie mit der Zeit vernichtet, und nun erkennen alle Aerzte hier die contagiöse Natur der Phthisis an. Das würde sich auch nach einer gewissen Periode in Bezug auf die Anschaung über die ätiologische Natur der Lepra herausbilden. Was das Auftreten von Syphilis in Europa geschichtlich anbelangt, so glaubt D. an die Worte eines Schriftstellers am Ende des 15. Jahrhunderts, der von der Syphilis sagt: "Novum genus morbi incubuit terras."

Blaschko (Berlin) meint, dass Lepra ebensowenig in Ost-Preussen als anderswo autochthon entsteht. In den erstgenannten Ort wurde sie vielmehr durch den menschlichen Verkehr von Russland aus eingeschleppt. (Vide Sonnabend-Verhandlung.)

Jadassohn (Breslau) hält einen Vortrag über einige seltenere Hautsyphilide und bringt $F$ olgendes vor: 1 . Unter den verschiedenen Gruppirungsformen der syphilitischen Exantheme sind die centralen Efflorescenzen zu wenig beachtet worden. Ihre Characteristica, wie sie sich vor Allem bei der: "Syphilis corymbosa" zeigen, sind:

a) Die centrale Efflorescenz ist die älteste; die peripheren erreichen nicht den Grad der Entwickluung wie die centralen.

b) Diese Form kommt schon bei der Roseola vor, sie bedingt gruppirte, maculöse Syphilide in der Frühperiode.

c) In der Spätperiode ist sie selten.

d) Die Form ist diagnostisch wichtig, da sie bei anderen Dermatosen nur ganz ausnahmsweise vorkommt.

2. Der Ansicht von Lang, wonach die von ihm beschriebenen "lupoiden" Herde bei Spätlues auf eine Mischinfection mit TuberkelBacillen zurückzuführen sind, schliesst sich J. vollkommen an und fügt noch dazu, dass dasselbe auch bei allerdings sehr seltenen, schweren: papulösen Formen der Fall sein kann.

3. Die Differential-Diagnose zwischen secundärer und tertiärer Lues ist bei vielen Formen morphologisch ganz sicherzustellen. Jodkalium hält der Redner für ein ausgezeichnetes differential-diagnostisches Mittel insofern als die Patienten auf die Verabreichung desselben reagiren oder nicht - zwischen Früh- und Spät-Syphilis.

Ernest Lane (London). On the treatment of syphilis by Intravenous Injections of Mercury. (Die Behandiung der Syphilis mittelst intravenöser Mercur-Injectionen.) 
Bacelli hatte diese Behandlungsmethode 1893 empfohlen. Seitdem wurde dieselbe von verschiedenen Autoren geprüft. Um dieser $\mathrm{Me}$ thode genügend Kenntniss und Erfahrung abzugewinnen, hatte sie Lan e während der letzten 9 Monate bei syphilitischen Patienten, die das London Lock Hospital aufsuchten, angewendet. Diese Behandlungsmethode, so bemerkt L., kann unzweifelhaft mit allen bis jetzt in der Syphilis-Behandlung bewährten Methoden - z. B. Inunctionen, intramusculäre Injectionen, interne Verabreichung - wohl wetteifern; der Vortheil aber der intravenösen Injectionen geht all den übrigen ab, nämlich dass die Palienten dadurch sehr schnell dem Einflusse des Mercurs ausgesetzt werden. Die Technik der Methode, der er sich bedient, ist kurz folgende: Eine Ligatur wird ring 3 um den Vorderarm gelegt; die Injectionsnadel wird dann sofort in eine der meist hervortretenden Venen in der Nähe des Ellenbogen-Gelenkes eingeführt. In diesem Moment wird die Ligatur entfernt und die Injection ausgeführt. Nach Entfernung der Nadel wird die Punctionsstelle für einige Momente mit dem Finger zugedrückt; eine vorhergehende, gewöhnliche, antiseptische Reinigung des Operationsfeldes ist rathsam. Es sei nicht nothwendig, für Ausführung der Injection einige Bluttropfen aus den angestochenen Venen emporquellen zu lassen, da durch das Hin- und Herbewegen der Nadel beurtheilt werden kann, ob die letztere in das Lumen der Gefässe eingedrungen ist oder nicht. Ferner haben wir an der der Injection folgenden Schwellung, Schmerzen etc. einen guten Anhaltspunkt der Selbstiversicherung, ob die Injection in die Venen hinein oder in das benachbarte Gewebe gemacht worden ist, da nur im letzteren Falle solche Frscheinungen aufzutreten pflegen. In die Vena mediania basilica wurde für gewöhnlich injicirt; weder eine Thrombosis, noch irgend welche Alteration der Gefässwandung wurde beobachtet. Die Methode wurde ansschliesslich an weiblichen Patienten geübt. Ihre Zahl betrug 76 und die ausgeführten Injectionen zählen über 1000. Von Complicationen erwähnt L. Polyurie und eine sehr leichte Albuminurie, die bei einigen Patienten unmittelbar nach der ersten resp. zweiten Injection auftraten. Fine besondere resp. eine Unterbrechung der Behandlung erforderten sie nicht, weil sie sich von selbst bald wieder verloren. Eine andere Erscheinung, über die viele der Patienten klagten, war metallischer Mundgeschmack, der sich gleich nach der Injection einstellte. Die Kranken, die L. auf die eben geschilderte Weise behandelte, befanden sich, wie wir uns aus den herumgereichten Listen überzeugen konnten, in allen möghichen Stadien und zeigten alle möglichen syphilitischen Erkrankungs-Formen.

Justus (Buda-Pest) hat in den letzten zwei Jahren circa 70 Kranke mit Injection von Sublimat behandelt; die angewandten Dosen variirten zwischen $1 / 2$ und $20 \mathrm{mg}$. Die Resultate waren keineswegs ermuthigend. Lang fortgesetzte Behandlung hatte kaum sichtbaren Einfluss auf die vorhandenen Symptome. Dagegen war es späterhin nicht mehr möglich, eine Vene zu finden, die noch nicht obliterirt war und ganz oberflächlich verlief. Eiweiss im Urin war nach der Injection nicht zu finden. Dagegen 
war nach Verlauf von 24 Stunden der Urobilin-Gehalt bedentend vermehrt.

Blaschko (Berlin) hatte sich gelegentlich der Versammlung deutscher Naturforscher und Aerzte in Wien dahin ausgesprochen, dass diese Methode praktisch wenig brauchbar ist und zwar wegen des Umstandes, dass die Venen allmälig durch Phlebitis oder wandständige Thrombosen veröden. An diesen Bemerkungen hält $B$. noch jetzt fest, und seine Erfahrungen belehrten ihn dahin, dass man oft nach 10-12 Injectionen keine Venen mehr findet, die sich dafür. eigneten.

Augustus Ravogli (Cincinnati- Ohio, U. S. A.) macht mit Recht darauf aufmerksam, dass gerade bei Syphilis jeder Fall individuell behandelt werden müsse. R. sagt, dass kein Grund vorliege, bei anämischen und hysterischen weiblichen Individuen durch zahlreiche Injectionen die bereits vorhandenen nervösen Erscheinungen zu steigern. Während ihm sechs bis acht intramusculäre Injectionen günstige Resultate geben, so ist doch wahrlich kein Grund vorhanden, die intravenöse Methode anzuwenden, die ungefähr 40 Injectionen erfordert.

Feibes (Aachen) empfiehlt, wenn rasches Eingreifen erforderlich, Calomel-Injectionen, die für ihn viel energischer und rascher wirken und deswegen zuverlässiger sind, als die eben von Lane vorgetragene Methode. Ist die Wirkung erzielt, so sind Einreibungen dann am Platze.

Jullien weist auf die Schwierigkeit dieser Methode hin und speciell bei Frauen, wo man die Haut-Venen nicht leicht findet.

Mittwoch, 5. August 1896. 2. Verhandlungstag.

Die Vormittagssitzung des zweiten Verhandlungstages in der Section für Dermatologie war der folgenden Discussion gewidmet:

Aetiologie und Varietäten der Keratosis. (The Etiology and Varieties of Keratosis.)

Unna (Hamburg). Ueber das Wesen der normalen und pathologischen Verhornung.

Während noch vor einem Decennium die Ansichten über den normalen Verhornungsprocess weit auseinander gingen, hat sich jetzt eine Einigung der Ansichten darüber ausgebildet. Dies spricht noch nicht dafür, dass auch über den hier zu besprechenden pathologischen Process Einigung herrscht. Redner behandelt das Thema nach den drei folgenden Seiten: 1. Von der mikroskopisch-klinischen Seite, 2. mikroskopisch-histiologischen, 3. chemischen.

Die Resultate der Forschungen, die auf dem Wege der Mikroskopie und Mikrochemie erzielt worden sind, lassen die folgende Definition der normalen Hornzellen zu: Hornzellen sind Oberhautzellen (Zellen der äusseren Keimblätter), welche ein hartes, trockenes, mehr oder weniger 
transparentes Gewebe darstellen und sich durch Verdauungs-Fermente nicht auflösen lassen. Die bisherigen Theorien über den normalen, histologischen Process der Verbornung zerfielen in drei Gruppen:

1. Die erste Theorie war, dass das Innere der Zellen zunächst diesen Process eingehe; 2. dass der Mantel der Zelle zuerst in Verhornung übergeht, und 3. dass beide Theile daran gleichmässig participiren.

Was den Verhornungsprocess im Innern der Zelle betrifft, so glaubte Sabludowski fertiges Keratin im Centrum der verhornten Zeilen des Vogelschnabels beobachtet $z u$ haben. Waldeyer erklärte es als Keratohyalin, schrieb demselben die Eigenschaft zu, sich mit gewissen Theilen des Zellprotoplasmas zur Bildung von Keratin zu vereinigen, und sprach sich weiter noch dahin aus, dass das erstere verdaulich ist. Reinicke hat im Innern der Zellen eine durch basische Farben färbbare Substanz gefunden, die er Pro-Keratin nennt. Die beiden letzteren, von W ald e yer und Reinicke aufgestellten Theorien sind in vollem Widerspruche zu den jüngst auf dem Wege der Pepsin-Verdauung gewonnenen Thatsachen, nämlich, dass der gesammte Inhalt der Hornzelle der normalen Oberhaut "mit grosser Leichtigkeit und Vollständigkeit verdaulich ist."

Nach Cajal spielt sich der Verhornungsprocess im Zellmantel ab und die innere Substanz der Zelle und selbst der Kern nehmen erst consecutiv an diesem Process Antheil. Vortragender hat bekanntlich 1882 auf Grund von Verdaungsversuchen die Theorie aufgestellt, dass der Verbornungsprocess lediglich im Zellenmantel stattfindet und zwar betrifft er zunächst: die äusserste Peripherie der Zelle, das heisst in der Breite von kaum $1 \mathrm{Mm}$ Freilich treten auch im Inneren der Zellen Verhornungen auf, aber diese sind nun nach dem hedner als Folge- resp. Begleiterscheinungen des in der Peripherie der Zelle vor sich gehendex Verhornungsprocesses zu verstehen, stofflich aber tragen die letzteren nichts zu der Verhornung bei. Die Definition der verhornten Oberhautzelle müsste jetzt nach Unna in folgender Weise lauten: Hornzellen sind Oberhautzellen, weīche milsroskopisch ein hartes, trockenes, mehr oder weniger transparentes Gewebe darstellen und in Verdauungssäften sich nicht anflösen, sondern dabei eine unverdauliche, aus Keratin bestehende Hüllmembran zurücklassen.

Soviel was den histologischen Standpunkt der Frage der Verhornung anbelangt, die Chemie dieses Capitel, die die histologischen Erforschungen ergänzen und vervollkommnen soll, hat mit den letzteren bis jetzt in keiner Weise gleichen Schritt gehalten. Es ist für den Chemiker, der an die Bearbeitung und Erforschung dieses Themas herangeht, nothwendig, folgendes nicht ausser Acht zu lassen: 1. Dass in den normalen Hornzellen die Verhornung sich nur auf den äussersten Zellensaum beschränkt. 2. Die Kerne, das Keratohyalin und das Eleidin haben mit dem Process der Verhornung nichts zu thun. 3. Dass das Keratin ein einfach chemischer Körper ist, der vielleicht dem Protoplasma in gewissen Beziehung sehr nahe steht. 4 . Ferner ist es nicht richtig; in der normalen 
Hornsubstanz der Deckepithelien Kernsubstanz oder etwaige Abkömmlinge derselben zu suchen.

Was den Status nascendi des Keratins anbelangt, so sprechen die chemisch gewonnenen Erfahrungen dafür, dass es sich rom Eiweiss, was seine qualitative wie quantitative chemische Zusammenstellung betrifft, nur sehr wenig unterscheidet, und wenn ein chemisch nachweisbarer Unterschied zwischen den beiden Körpern bestünde, so wäre dies in dem grösseren Gehalt des Keratins an Schwefel zu suchen. Noch ein weiterer chemischer Unterschied lässt sich zwischen den beiden Körpern beobachten und verdient besonders hervorgehoben zu werden, dass nämlich, während Eiweiss bei der Zersetzung viel Leucin liefert, aus der Zersetzung des Keratins mehr Tyrosin als Leucin resultirt. Die Wasserabgabe des Keratins darf nicht als besonderes Charakteristicum des letzteren dargestellt werden. Die letzten drei erwähnten Eigenschaften des Keratins führen kurz zu folgenden Schlüssen : 1. Keratin ist Protoplasma mit für die Structur und Constitution unwesentlichen Veränderungen. 2. Es ist ferner, im Ganzen genommen, schwerlich anzunehmen, was von verschiedener Seite behauptet worden ist, „dass eine tiefgehende Zersetzung im Eiweiss der Bildung von Keratin vorhergeht."

Wie geschieht die Verhornung des Protoplasma? Es ist sehr wahrscheinlich und theoretisch wohl denkbar, dass die auf dem Lymphwege den Oberhautzellen zugeführten Stoffe, wie Schwefel und Phenol, auf das Protoplasma einen gewissen Einfluss üben und den Process der Verbornung hervorrufen. Zwar stellt der Redner das Letztere als für vollständig nachgewiesen hin. Indess wir können uns dieser Auffassung nicht ganz anschliessen, and wir wollen dieselbe nicht mehr und nicht weniger als eine wahrscheinliche, viel für sich habende Hypothese hinstellen. Während man beim Studium des normalen Verhornungsprocesses auf viele Schwierigkeiten stösst, bieten sich dieselben in einem noch viel grösseren Massstabe beim Studium des pathologischen Verhornungsprocesses, dessen Hauptrepräsentanten, wie wir hier gleich bemerken wollen, Unna, „den Clavus, die Psoriasis und die Ichthyosis" nennt.

Auf die Technik der Methode übergehend, empfieblt der Vortragende die Anlegung feiner Schnitte, die Beobachtung einer gleichmässigen Temperatur von etwas über $40^{\circ}$. Wenn auch eine vorhergehende Entfettung nicht absolut nothwendig ist, so beschleunigt sie toch die nachfolgende Verdauung. Von allen Verdauungsfermenten, wie Pepsin, Tripsin, Pancreatin etc. ist dasjenige, bestehend aus Pepsin und Salzsäure doch noch am besten zu empfehlen und zwar etwa in der folgenden Form: Aqua 100.0, Acid. hydrochlor. 1.0, Pepsin 0.5.

Aus seinen Untersuchungen, die ihn vornelmlich das letzte Jahr" beschäftigten, lassen sich noch folgende Schlüsse ziehen:

1. Reichthum an Keratin und die klinischen Erscheinungen der Hauthärte gehen nicht immer einander parallel; 
244 Bericht über den 3. internationalen dermatolog. Congress, ist, und

2. dass auch die pathologische Verhornung eine Randrerhornung

3. dass die Differenzen bei den verschiedenen Formen der Keratose auf die Dicke der Balken und Weite der Maschen des Hornnetzes sich beschränken. In Weiterem empfiehit Unna das Studium des HornzellenReliefs für die Pathogenese der Hypo-Keratosen.

Brooke (Manchester) entwirft ein Schema für die Classification der Hyperkeratosen. Um aber die Uebersicht mit Bezug auf die verschiedenen Formen, wie sie sich ätiologisch von einander unterscheiden, zu erleichtern, scheidet er aus diesem Schema die sogenannten secundären Hyperkeratosen, die sich auf dem Boden maligner und granulöser Geschwïlste, wie Carcinom, Lupus, Syphilis entwickeln, aus. Um es noch anschaulicher zu machen, theilt er die Affectionen, je nachdem sie die Tendenz besitzen, sich auszubreiten, oder stationär zu bleiben, in regionäre und allgemeine ein. Dabei berücksichtigt er noch den anatomischen Cmstand, nämlich ob die Affection sämmtliche Hautelemente oder nur einige derselben ergreift. Auf diesem Wege gelang es ihm folgende Classification aufzustellen.

Primäre Hyperkeratosen.

Allgemeine. Ichthyosis. Acrokeratoma.

Pityriasis rubra pilaris.

Hyperkeratosis universalis congenita.

Lichen pilaris.

Keratosis pilaris.

Keratosis follicularis, contagiosa.

Comedo $\left\{\begin{array}{l}\text { Acne comedo } \\ \text { Comedo atrophicans. }\end{array}\right.$

Lichen planus.

Keratosis multiplex congenita.
Regionäre.

Kératodermie symmétrique

des extremités.

Erythema keratodes.

Keratoma palmare et plantare hereditarium. Multiplex.

Lichen spinulosus. Verruca.

Callus. Clavus.

Keratosis arsenicalis.

Kératodermie des extremiteés en foyers.

Hyperkeratosis subungualis.

Angiokeratoma.

Onychogryphosis.

Cornu cutaneum.

Naevus lkeratodes linearis.

Vortragender weist noch auf die Thatsache hin, dass die regionäre diffuse Gruppe die einzige ist, deren Mitglieder eine wirkliche Verwandtschaft und eine reale Aehnlichkeit zu einander besitzen. Sie sind meist auf eine bestimmte Fläche beschränlt, d. h. auf die palmare Fläche der Hände und Füsse. Es unterliegt fermer keinem Zweifel, dass sie trophischen und es ist sehr unwahrscheinlich, dass sie trophoneurotischen Ursprunges sind. Seine Argumente, die gegen ihren trophisch-neurotischen. 
Ursprung sprechen, sind, dass sie sich auf Theile des Körpers beschränken, welche schon in normaler Weise zu Hyperkeratosis Veranlagung zeigen.

Pityriasis rubra pilaris, fasst er als eine Krankheit infectiösen Ursprunges auf, wozu ihn der Umstand veranlasst, dass diese Affection in. bestimmten Gegenden häufiger resp. seltener zur Beobachtung gelangt.

Acne Comedo. Keratosis pilaris, Lichen pilaris, Keratosis follicularis contagiosa (die drei zuletzt genannten Formen der Keratosen unterscheiden sich nach $B$. von der Ichthyosis durch die zwei folgenden Merkmale: 1. Sie bleiben strict begrenzt an einer Stelle; 2. sie zeigen ganz andere horn-histologische Veränderungen auf), und auch wohl Lichen planus fasst der Redner als contagiös auf. Bei Ichthyosis und Acrokeratoma lassen sich die anatomischen Veränderungen vielleicht auf einen trophischen, möglicher Weise auf einen toxischen Ursprung zurück führen. In der Aetiologie von Callus und Clavus spielt mechanischer Druck (Anaemie?) die Hauptrolle. Keratosis arsenicalis ist sicherlich toxischer Natur; bei vielen anderen sind natürlich Ursache wie Aetiologie noch nicht aufgeklärt. Infectiöser Natur sind nach B. Verruca, wahrscheinlich auch die Hyperkeratosis subungualis, möglich auch der Lichen spinulosus.

W. Dubreuilh (Bordeaux) gibt eine Classification an, die namentlich der Aetiologie der verschiedenen Keratosen-Formen entspricht.

Am Nachmittage des zweiten Verhandlungstages wurden folgende Vorträge gehalten:

Prof. Schwimmer (Budapest) hält einen Vortrag über Sarcom d e r H a u und einige verwandte Affectionen. Das Sarcom zeigt sich in zwei Formen: die eine Form ist das sogenannte chirurgische Sarcom, das oft durch locale Reizung entsteht, die andere Form ist das von Kaposi vor mehr als zwanzig Jahren beschriebene Pigmentsarcom. Bei der letzteren bilden die Extremitäten - z. B. die Finger der Eände oder der Füsse, Vorderarm, Unterschenkel und, wie jüngst vom Vortragenden beobachtet, auch der Oberschenkel - den Ausgangspunkt für diese Affection. Von besonderem Interesse sind die vom Autor mitgetheilten Autopsiebefunde. Es handelte sich dabei um zwei Kranke, die an typischen Formen der eben beschriebenen Affection litten. Die Obduction ergab Sarcom-Neubildungen im. Dick- und Dünndarm und namentlich im. Magen. Im Gegensatz zu anderen Dermatologen trennt S. die Mycosis fungoides von den Sarcomerkrankungen und will die. erstere als eine selbständige Krankheit betrachtet wissen. Dies erörtert. er an der Hand der von ihm ausgeführten, hierhergehörigen, histologischen Untersuchungen, dass, wiewohl beide Affectionen von den Bindegewebszellen ausgehen, im Sarcom hauptsächlich Spindelzellen, dagegen in der Mycosis fungoides Rundzellen vorkommen. Ein weiterer Unterschied zwischen beiden Krankheitsformen besteht noch darin, dass bei der letzteren die Lymph-, bei der ersteren die Blutgefässe afficirt sind. 
Der Vortragende zeigt noch zum Schlusse eine gelungene Abbildung ron einem Falle, der zuerst die klinischen Erscheinungen einer Mycosis fungoides bot, später aber, namentlich durch histologische Untersuchungen, als ein Fall von einfacher Cranulom-Bildung sich herausstellte.

M. Joseph (Berlin). Deber Lichen ruber planus, acuminatus und verrucosus.

Um seinen Vortrag noch anschaulicher zu machen, veranstaltete Joseph eine ausgedehnte mikroskopische Demonstration, die dem Vortrage vorausging und bereits am ersten Sitzungstage im Museum des Congresses abgehalten worden war. Der Kern des Vortrages besteht darin, dass der Redner an der Hand vielfacher, histolologischer Untersuchungen zu zeigen sich bemüht, dass der Lichen ruber planus, accuminatus, verrucosus und die Pityriasis rubra zu einander in einem sehr engen Zusammenhange stehen. (Die ausführliche Arbeit erscheint demnächst in diesem Arehiv.)

Gaucher (Paris). Behandlung von Haut-Epitheliomen.

In diesem seinen Vortrage stellt $G$. die Cauterisation an die Spitze der hier in Betracht kommenden Behandlung und verwirft alle anderen Methoden, die nicht direct das neugebildete, krankhafte Gewebe zerstören, sondern womöglich durch eine unvermeidliche Eröffnung kleinerer Gefässe die Ausdehnung der Geschwülste in das benachbarte Gewebe und die Bildung von Metastasen zu Wege bringen.

Zefarino Falcao (Lisbon) berichtet über 4 von ihm beobachtete Fälle von Xeroderma pigmentos a m, das ältere Individuen betraf, und in allen waren die von Kaposi beschriebenen Symptome dieser Krankheit 2ngegen. Das Xeroderma pigmentosum kommt in jedem Alter vor, !bei ganz jugendlichen Individuen ist der Pigmentationsprocess stärker ausgesprochen wie bei älteren; bei letzteren, und namentlich wenn es in einem höheren Alter auftritt, ist der Atrophie- und Verhärtungsprocess stärker entwickelt.

Wickham (Paris) trägt über einen Fall von Rhinosclerom vor, in dem - Vortragender versuchte zuerst alle anderen dafür empfohlenen Mittel, wie z. B. Arsen-Injectionen, Verabreichung ron Jodkalium, locale Cauterisation etc., ohne jeden Erfolg - die von französischen Autoren genannte "grande Operation" ausgeführt war. Die dadurch erzielten erfreulichen Resultate ermuntern W., sich dahin zu äussern, dass in schweren Fällen dieser Erkrankung keine Zeit mit anderen therapeutischen Maassregeln verloren gehen, und sofort zur Operation geschritten werden soll.

o. Rosenthal (Berlin). Ueber Heisswasserbehandlung bei Hautkrankheiten.

Zunächst gibt der Autor einen kurzen, geschichtlichen Ueberblick über die Anwendung des Wassers in dermatologischen Fällen. Er weist zunächst auf die physiologisehe Wirkung des heissen Wassers (von $40^{\circ} \mathrm{R}$. $=50^{\circ} \mathrm{C}$. und darüber) auf den thierischen Organismus hin und unterscheidet 
dabei eine locale und eine allgemeine Wirkung, letztere mit Bezug auf Circulation und Nervensystem. Der Einfluss auf die Hautoberfläche besteht darin, dass die Perspiration vermehrt wird; es folgt darauf eine Beschleunigung des Stoffwechsels, und der Gasaustausch geht schneller vor sich. Er gibt verschiedene Formen, in denen das Heisswasser zur eventuellen Anwendung gelangen könnte an (Stirn-, Hand-, Fuss- und Tnterschenkelbäder). Redner streift nun die Frage, ob Herzaffectionen eine Contraindication für Heisswasserbehandlung abgeben, und meint, dass nur directe Erkrankungen der Gefässwandungen, wie die Atheromatosis etc., eine solche dagegen bieten. In der Dermatologie wird das heisse Wasser zu einem Theil als directes Heilmittel herangezogen, andererseits wird es auch zur Erfüllung und Unterstützung anderer Indicationen gebraucht. Ob diesem Verfahren und speciell in der besprochenen Forro eine antispecifische Wirkung zutommt, ist eine weitere Frage; R. allerdings scheint es für erledigt zu halten, und meint, dass diese Behandlung eben wegen ihrer "bactericiden" Wirkung bei Ulcus molle, Gonorrhoe, Favus und zerfallenen Ulcerationen, specifischer oder nicht specifischer Natur, empfohlen werden darf. Bei Eczema scroti und Vulvae, bei chronischen circumscripten Hautläsionen leistet nach $R$. die locale Heisswasserbehandlung "treffliche Dieuste".

Bei der Syphilis würde die Heisswasserbehandlung die Hg.-Wirkung unterstützen und die Ausscheidung des $\mathrm{Hg}$. beschleunigen.

v. Petersen (St. Petersburg) bemerkt, dass wir noch immer unter den Dermatologen Hydrophoben haben, d. h. Collegen, die sich vor Wasserbehandlung in Hautkrankheiten fürchten. Er äussert sich noch dahin, dass in St. Petersburg jetzt immer häufiger locale Wärme angewandt wird (trockene Wärme [Leiters Apparat] oder in Form von heissen Compressen). - Dr. Ussas soll, wie P. hervorhebt, schon seit Jahren mit vielem Erfolg schwere und hartnäckige Syphilis-Eruptionen mit heissen Compressen behandelt haben.

E. Schiff (Wien). Ueber ein neues Vehikel zur Application von therapeutischen Substanzen, die in der Dermatologie gebraucht werden.

Die Vorzüge des von S. hergestellten Präparates, das er mit dem Namen "Filmogen" belegt, schildert der Vortragende in folgender Weise: 1. Es bildet eine Art Oberhaut über die ergriffene Hautpartie. 2. Da die erstere von elastischer Beschaffenheit ist, so folgt sie allen Verschiebungen und Bewegungen der Haut. 3. Ein Aufbrechen des so künstlich gemachten Ueberzuges der Haut ist daher ausgeschlossen, und 4. was in therapeutischer Hinsicht für $\mathrm{S}$. die Hauptsache ist, die auf die Haut zu applicirenden, medicamentösen Substanzen können nach Belieben lange zur Entfaltung ihres heilenden Einflusses auf die afficirten Partien erhalten bleiben. 5. Die so mit dem Präparate bestrichenen Stellen können, ohne irgendwelchen Nachtheil zu erfahren, gewaschen werden, da das Präparat in Wasser unlöslich ist. 


\section{Donnerstag, 6. August. 3. Sitzungstag.}

\section{Section für Dermatologie.}

Der Zusammenhang von Tuberculosis mit Hautaffectionen mit Ausschluss von Lupus vulgaris. (The connection of tubercalosis with diseases of the skin other than lupus vulgaris.)

Als officielle Referenten über dieses Thema haben wir zu nennen:

1. Dr. Nevins Hyde (Chicago). 2. Dr. Hallopeau (Paris). 3. Dr. Radcliffe Crocker (London).

N. Hyde glaubt, dass eine primäre und secundäre Infection der Haut mit Tuberkelbacillen allgemein angenommen wird. $\mathrm{Zu}$ inneren tuberculösen Erkrankungen kann secundär eine Dermatitis hinzutreten, die aber keine Tuberkelbacillen zu enthalten braucht. Freilich bietet die Hant-Tuberculosis kein einheitliches klinisches Bild, aber dies lässt sich durch den Umstand erklären, dass nicht in jedem Falle die Tuberkelbacillen allein die krankhaften Erscheinungen hervorrufen, sondern, dass noch zu denselben andere Mikroorganismen gelangen, die dann die gesetzten Erscheinungen nach der einen oder der anderen Richtung hin ändern. Ein anderer Umstand für die Multiplicität des Krankheitsbildes kommt noch in Betracht, nämlich die anatomische Lage und die histologischen Substrate desjenigen Körpertheiles, der von den Tuberkelbacillen invadirt wird. $\mathrm{H}$. entwirft noch eine Classification der Symptome der Haut-Tuberculosis - Lupus vulgaris ist natürlich dabei ausgeschlossen die sich etwa in die drei folgende Gruppen unterbringen lässt:

1. Hautläsionen, die durch eine primäre oder secundäre Infection mit tuberculösem Virus bedingt sind.

2. Hautläsionen, in denen die Anwesenheit des Tuberkeibacillus bis jetzt noch nicht erbracht worden ist, wobl aber sich vielleicht bei weiteren Untersuchungen als der wirkliche Krankheitserreger herausstellen wird.

3. Tuberculosis der Haut, die etwa anf metastatischem Wege zustande kommt.

In die erste Kategorie stellt der Vortragende die folgenden klinisch bezeichneten hrankheitsformen der Hatt:

1. Verruca necrogenica. 2. Tuberculosis verrucosa cutis (Riehl und Paltauf). 3. Tuberculosis papillomatosa cutis (Morrow's Typus). 4. Fibromatosis cutis (RiehI). 5. Elephantiasis tuberculosa cutis. 6. Tuberculosis cutis ulcerativa (Chiari). 7. Tuberculosis gummatosa ulcerativa. 8. Lymphangitis tuberculosa cutanea (Besnier). 9. Tuberculosis cutis serpiginosa ulcerativa. 10. Tuberculosis cutis fungosa. 11. Tuberculosis nodosa atrophica (lupoide Form).

In die zweite:

1. Lupus erythematosus. Dazu müsse noch bemerkt werden, dass diese Form bei nicht tuberculösen Individuen beobachtet wird; die Natur 
ihres Entstehens sei allerdings noch nicht aufgeklärt. Lupus eryth. kommt freilich bei tuberculösen Individuen vor, und die Wahrscheinlichkeit, dass hier zwischen allgemeiner Tuberculosis und Lupus eryth. ein engerer Zusammenhang besteht, sei eine sehr grosse.

2. Erythema induratum scrofulosorum (Bazin). 3. Lichen scrofulosorum. 4. Tuberculosis suppurativa et bullosa acuta (Hallopean).

In der dritten endlich nennt $\mathrm{H}$.:

1. Eczem-Affectionen (Neurodermitiden). 2. Erythema pernio. 3. Seltene Fälle von Erythema multiforme. 4. Einige Fälle von Melanoderma. 5. Die sogenannte Puryura cachecticum, und 6. medikamentöse Dermatosen.

H. Haliopeau (Paris). Ob ein Hautleiden tuberculöser Natur ist oder nicht, kann durch die folgenden Punkte entschieden werden:

1. Durch den Nachweis typischer Bacillen;

2. Durch das Resultat der Inoculation im Allgemeinen und der weiteren Fortimpfung im Besonderen. Von der Virulenz der Tuberkelbacillen hängt es ab, ob sich eine ulcerative, supurative, ulceröse Läsion der Haut entwickelt; die Form der Erkrankung wiederum hängt davon ab, in welchen Elementen der Haut die ebengenannten Bacillen sich ansiedeln. Es wird natürlich ein ganz anderes klinisches Bild auftreten, wenn die Tuberkelbacillen zuerst in den Papillarkörper, die Lymphdrüssen etc. gerathen. So entsteht der Lupus verrucosus, wenn die Papillarköryer der Haut tuberculös erkranken, so entwickeln sich die gummösen Geschwüre, wenn das Lymphsystem zuerst von den Bacillen durchsetzt wird. Verschiedene Krankheitsbilder der Haut, die durch Knötchenbildung sich auszeichnen und demnach in ihren äusseren, wie inneren histologischen Erscheinungen der Tuberculosis nahesteben werden aus der letzteren nur aus dem Crrunde getrennt, weil man in denselben bis jetzt noch keine Tuberkelbacillen gefunden hat. Dies scheint aber nicht ganz richtig zu sein und die Thatsache, dass solche Kranke auf Tuberculin-Injectionen zu reagiren pflegen, ferner, dass der Verlauf dieser Krankheitsformen an den Lupus verrucosus erinnert, die serpiginöse Form des Hautleidens, die solche Patienten aufweisen, spricht doch sehr dafür, auch bei ihnen einen einheitlichen tuberculösen Process anzunehmen. Lichen scrofulosorum, Acne cachecticum sind für $\mathrm{H}$. der Ausdruck einer Tuberculosis. Mit Vidal, Paltauf und Riehl zählt noch H. zu den Haut-Tuberculosen die sogenannte sclerotische (Vidal) und die verrucöse Form (Riehl und Paltauf). Die tuberculöse Natur der Impetigo rodens ist durch Gaucher nachgewiesen worden. Es hat sich gezeigt, dass die sogenannte supurative Folliculitis in Tuberculosis entarten kann. Hallopea u und $\mathbf{R}$ oger bedienten sich einiger Experimente, die darin bestanden, Streptococcen-Culturen aus Erysipelas gezüchtet, auf lupöse Herde zu übertragen. Aber in Anbetracht der geringen Anzahl der von H. und R. damit auss geführten Untersuchungen, verzichtet der Redner vorderhand Bestimmtes über diese Behandlungsmethode auszusagen. 
Crocker, der über einschlägige Krankheitsfälle referırt und hierher gehörige, interessante Abbildungen vorlegt, meint, dass eine Reihe von Hautläsionen vorkommt, deren Entstehung auf eine directe, unzweifelhafte Invasion von Tuberkelbacillen zurückzuführen sei.

Jadossohn (Breslau). Lichen scrofulosorum.

Die auffallend häufige Combination von Pityriasis rubra Hebrae mit Tuberculose wird von. J. betont, dagegen der Zusammenhang von Lupus eryth. mit Tuberculosis bezweifelt; eher würde der Vortragende den Lichen scrofulosorum in die Kategorie der letzteren bringen, da es ihm in 19 Fällen gelungen ist, vierzehnmal sichere Tuberculose und viermal andere scrofulöse Zeichen nachzuweisen, und nur in einem Falle aus dieser Gruppe war nichts von Tuberculose vorhanden. J. drückt sich daher dabin aus, dass der Lichen scrof. eine Krankheit der Tuberculösen und nicht der Cachectischen ist.

Campana (Rom). The mode of action of Tuberculin (Wirkungsweise des Tuberculins).

Die vieljährigen Exfahrungen Campan a's mit Tuberculin bei tuberculösen Hauterkrankungen lassen sich kurz in folgender Weise zusammenfassen:

1. Das Tuberculin hat die Eigenschaft eines localen chemischen Irritans und setzt an die Stelle der chronischen, tuberculösen Entzündung eine acute. Letztere erinnert an diejenige Dermatitis, wie sie durch Chrysarobin hervorgerufen wird.

2. Tuberculin-Injectionen bringen Iupöse Infiltrate zum Verschwinden, verhindern allerdings nicht weitere Recidive.

Wickham (Paris). Ueber Lupus erythematosus und Tuberculosis.

Gewisse Erytheme, die einen stationären Charakter aufweisen, werden bei tuberculösen Individuen beobachtet. W. machte jüngst eine Beobachtung, die für den ätiologischen Zusammenhang von Lupus eryth. mit Tubereulosis spricht. Der Fall betraf eine 48jährige Dame, die an Lupus erythematosus litt. Die Frau ging an diesem Leiden zugrunde, und die Autopsie ergab eine ausgebreitete Miliar-Tuberculose.

In einem weiteren Vortrag, betitelt: The value of multiple scarification in Eryth. Lupus (der Werth multipler Scarification in Lupus eryth.) demonstrirt Wickham ein praktisch brauchbares Instrument für diesen Zweck.

Audry (Toulouse) berichtet über einen Fall von „Eczéme éléphantiastique chez une tuberculeuse.

(Donnerstag, 6. August, Nachmittag im grossen Auditorium der Examination-Hall).

Discussion on Ringworm and the Trichophytons.

Sabouraud (Paris). Die Discussion über Ringwurm-Erkrankungen leitete Sabouraud ein. Seine Untersuchungen über diesen Gegenstand sind bekannt. 
Dasselbe gilt von dem Vortrage Rosenbach (Gottingen).

Malcolm Morris (London). Zunächst geht der Redner auf die hieher gehörigen Arbeiten von ein und beschreibt ausführlich die Methode, deren er sich bei den Untersuchungen und Anfertigung der Präparate bediente. Wir wollen gleich hier bemerken, dass Malcolm. Morris ganz besonderen Werth auf die sogenannte Färbe-Methode legt. Auch das wollen wir hier hervorheben, dass seine Untersuchungen sich auf die grosse $Z$ ahl von 126 Kranken erstrecken, und dass in nicht weniger als 116 Fällen (zur Untersuchung diente vornehmlich das Kopfhaar von Kindern), d. h. in 92\% der gefundene Parasit derjenigen Species angehörte, die sich durch kleine Śporen auszeichnet, bei den übrigen zehn Kranken jener der grossen Sporen. Nach dieser Richtung hin steht Morris' Statistik, die also das Vorkommen der zuerst genannten Parasiten in dieser Erkrankungsform auf $92 \%$ veranschlagt, im Gegensatz zu Sabourauds Statistik, der sie mit $60 \%$ angibt. Morris' Statistik wiederum, die er für London entwirft, steht aber dafür in vollem Einklange mit den Berechnungen für Edinburgh, wie sie Jamieson, Adamson und C. Fox anfgestellt haben. In Italien und Deutschland, fährt M. fort, scheint das Forkommen dieses Parasiten noch seltener als in Frankreich zu sein. Dafür sprechen eben die Beobachtungen von Mibelli und Krösing. Culturen der ersteren unterscheiden sich wesentlich vou der der letzteren Species, und als besonders differentielles Mittel zwischen den beiden Specien betont M. das verschiedene Aussehen derselben. Die erstere Species bietet cine weisse, die Ietztere eine braunrothe Farbe. Obwohl der Autor Sabouraud's Doctrine, die das Vorkommen der ersteren Species von Parasiten auf die Kopfhaut allein verlegt; beipflichtet, so bestreitet er doch wiederum die von S. aufgestellte Multiplicität der der letzteren Species angebörigen Parasiten.

Donuerstag, 6. August. 3. Verhandlungstag.

\section{Section für Syphilis.}

Die Dauer der Ansteckungsperiode der Syphilis bildete das Thema in der Vormittagssitzung. (The Duration of the Period of contagion of Syphilis.) J. Hutchinson (London), Campana (Rom), Lassar (Berlin), Feulard (Paris) waren als ofticielle Referenten für diese Discussion gewonnen. Der erste Redner, J. Hutchinson, hält es für ein ausgemachtes Factum, dass sowohl während des primären wie secundären Stadiums, d. h. während das inficirte Individuum primäre oder secundäre Symptome der Syphilis bietet, das Blut und alle anderen Secretionselemente das specifisch syphilitische Virus enthalten, und werden die genannten Stoffe auf andere Personen überimpft oder übertragen, so würde daraus eine eventuelle syphilitische Infection resultiren. Was die Dauer der Ansteckungsperiode der Syphilis anbelangt, d. h. die Zeit betreffend, wo das syphilitische Virus aus dem Gewebe und Flüssigkeiten des inficirten. Individiums schwindet und somit die Gefahr der Uebertragung vorüber 
ist, so setzt der Redner die Dauer von zwei Jahren fest. Nach dieser Periode, also zwei Jahre nach Auftreten des Primär-Affectes, gestattet H. inficirten Patienten zu heiraten, und nimmt in der Regel von nach dieser Periode sich zeigenden mässigen Recidiven keine besondere Notiz. Von einem oder zwei Fällen abgesehen, hat H. während seiner vierzigjährigen Praxis keine unangenehmen Resultate gesehen. $\mathrm{Er}$ ist im allgemeinen geneigt denjenigen Beobachtungen mit Misstrauen zu begegnen, die dahin gehen, dass ein Mann zehn oder noch mehrere Jahre nach der ersten specifischen Infection seine Frau noch nachträglich syphilitisch inficirte. Seine Erfahrungen gehen ferner dahin, dass die zeitliche Dauer der hereditären Uebertragung länger bei Weibern als bei Männern anhält, und im allgemeinen scheint die zeitliche Dauer der syphilitischen Infection beim Weibe länger als beim Manne anzuhalten. So kann z. 13. eine Frau noch vier Jahre nach der ersten Infection ihren Mann specifisch inficiren. Ein weiteres Gesetz für die Ansteckungsfähigkeit der Syphilis drückt der Redner in der Weise aus, dass mit der Zeitdauer das syphilitische Virus in toto sich so zu sagen abschwächt oder eine Reduction seiner contagiösen Elemente sich herausbildet und die Folge davon würde sein, was übrigens für $H$. sicher ist, dass ein inficirtes Individuum am Anfange des zweiten Stadiums eher eine zweite Person inficiren würde als am Ende desselben. Eine hereditäre oder allgemeine Uebertragung während der tertiären Periode - nach $\mathrm{H}$. beginnt die tertiäre Periode unmittelbar nach Ablauf des secundären Stadiums - ist, von ausserordentlich seltenen Fällen abgesehen, ganz ausgeschlossen. Die Wirkung des Hg. scheint darin zu bestehen, dass es direct das syphilitische Virus angreift und zerstört; die Fortsetzung des Gebrauchs des Hg. scheint das Auftreten der secundären Symptome hintanzuhalten, denn letztere treten auf, sobald die Anwendung des $\mathrm{Hg}$. unterbrochen wird. Ein hereditär inficirtes Kind soll nach H. die Ansteckungskeime auf andere Personen zwar übertragen können, aber diese Ansteckungsfähigkeit dauert gewöhnlich nur ein, selten mehr als zwei Jahre.

Campana (Rom) berechnet die Zeitdauer der Ansteckungsfähigkeit eines syphilitisch inficirten Individuums auf drei Jahre, nach dieser Zeit. soll nach C., wenn eine genügende antisyphilitische Behandlung vorausgegangen ist, die Gefahr der hereditären wie der allgemeinen Uebertragung des syphilitischen Virus schwinden.

Lassar (Berlin). Das frühere Bestreben, bestimmte Gesetze und Regeln auch für solche Erscheinungen, die nicht genügend erforscht und geklärt waren, einzuführen, hat den Forschern in der allgemeinen Pathologie und speciell in der Syphilis grosse Schwierigkeiten auferlegt. Gerade bei Syphilis rächt sich die Uebertragung einzelner Erfahrungen auf die Allgemeinheit. Hier sind Conclusionen und Suppositionen wohl weniger, als wo anders, am Platze. Man hat einen allgemeinen Fehler dadurch begangen, dass man hierbei die Contagiosität von der Infectiősität nicht scharf genug trennte. Nag dies vielleicht durch den Umstand zu erklären sein, dass wir uns, so zu sagen, gewöhnt haben, die 
beiden ebengenannten Erscheinungen mit einander zu identificiren. Bei verschiedenen anderen Krankheiten und besonders bei der Syphilis erfahren wir oft genug; dass die Contagiösität sich verliere, ohne eine Rückwirkung auf die Infectiosität zu haben, die also demnach fortbesteht, während das Umgekehrte, dass ein krankhafter Zustand seine Contagiösität beibehält, dagegen seine Infectiosität sich verliert, schwerlich beobachtet wird. Und weiter, diejenige Erscheinung, welche darin besteht, dass von einer einzigen Papula unbegrenzt ausgedehnte Infiltrationen ausgehen, d. h. die sogenannte progressive Multiplicität oder Expansion der Krankeitsheerde, könnte wohl kaum anders als durch die Wirkung der Infection zu Stande kommen. In vielen syphilitischen Krankheitsformen ist es beinahe unmöglich, wenn wir den ganzen Zusammenhang nicht verfolgten, $z u$ entscheiden, in welchem Stadium der betreffende Patient sich befindet. Hg. bietet uns in seinen Effecten leider kein Unterscheidungsmittel dafür. Dass die Infectiosität gleich dauernd der Krankheit selbst ist, scheint viel für sich zu haben, obwobl anderseits nicht geleugnet werden kann, dass mit der Dauer der Krankheit, die Gefahr der Contagiösität abnimmt. Dass die Uebertragung von Syphilis in ihrem späteren Stadium zu den grössten Seltenheiten gehört, ist über jeden Zweifel erhaben, dass sie aber doch vorkommt, scheinen die von $\mathrm{L}$. bei dieser Gelegenheit vorgetragenen Fälle, wo eine syphilitische Uebertragung 10, 12, 15 resp. 16 Jahre nach der ersten Infection erfolgte, zu sprechen. Das Räthsel in Bezug auf die Frage der Ansteckungsfähigkeit der Syphilis ist noch keineswegs gelöst. Die Erfahrung lässt uns hier im Stiche, das Experiment sagt nur: "quod non"; die klinische Beobachtung gibt nur eine ganz unbestimmte Antwort, daher meint L. dass wir recht thun, wenn wir sagen: "Ignoramus".

H. Feulard (Paris) meint, dass man in der Dauer der Ansteckungsfähigkeit der Syphilis einen individuellen. Unterschied machen müsse. $\mathrm{Er}$ würde einem syphilitisch inficirten Patienten nicht vor Ablauf des vierten Jahres das Heirathen anrathen, da die ersten vier Jahre durch das Wiederauftreten und Wiederverschwinden von syphilitischen Manifestationen charakterisirt sind, Glücklicherweise selten, aber doch sicher kommen Fälle vor, in denen hereditäre Uebertragung selbst zehn Jahre nach der ersten specifischen Erscheinung beobachtet worden ist. Die lange Dauer der Syphilis hängt noch von anderen üblen Gewohnheiten (z. B. Rauchen) und anderen Umständen beim inficirten Individuum ab. Dass die Einleitung einer frühzeitigen Behandlung die Virulenz und die Dauer der Ansteckungsfähigkeit des Syphilis-Virus wesentlich abkürze, möchte F. sehr bezweifeln. Fr theilt im weiteren eine Reihe für ihn unzweifelhafter Fälle mit, in denen eine specifisch hereditäre Uebertragung $4,6,7,10,18$, 20 Jahre nach dem ersten Primär-Affect zu verzeichnen war.

Wickham (Paris) lässt die Dauer der Ansteckungsfähigkeit der Syphilis von ihrer Localisation abhängen, z. B. scheinen diese Fälle von längerer Dauer und somit von längerer Ansteckungsfähigkeit zu sein, wenn Mund-Ulcerationen sich entwickeln. 
Tarnoviky (Petersburg) berichtet über 1000 hierhergehörige Fälle. Während der ersten fünf Jabre nach der specifischen Infection zeigten 802 Patienten condylomatöse Erscheinungen, nach dieser Periode, d. h. nachdem die ersten fünf Jahre verstrichen waren, fanden sich syphilitische Zeichen bei 176 Kranken, nach zehn Jahren, von der Zeit der. ersten Infection gerechnet, liess sich bei 26 Kranken und nach $15 \mathrm{Jahren}$. bei $5 \mathrm{Kranken}$ typische syphilitische Symptome nachweisen. Daher stellt T. den Satz auf, 1. dass ein syph. Individuum während der ersten 15 Jahre, von dem Auftreten der ersten Erscheinungen an gerechnet, die Krankheit übertragen könne. 2. So lange die secundären Erscheinungen dauern, so lange ist ein Patient der weiteren Verbreitung der Krankheit fähig. Blaschko (Berlin) hat in einem Falle erfahren, dass ein Ehegatte wohl $5 \frac{1}{2}$ Jahre nach der Primär-Affection noch nachträglich seine Frau specifisch inficirte. Schwimmer (Budapest) zieht die Verabreichunggrösserer $\mathrm{Hg}$-Dosen den längere Zeit fortgesetzten kleineren vor. Drysdale (London) hält sehr viel von der Jodkalium-Behandlung in tertiärem Stadium. Fitz Gibbon erwähnt einen Fall, der zeigen soll, wie unvorsichtig manche Aerzte mit dem Aurathen von Heiraten bei syphilitischen Personen vorgehen. Balzar nennt die Behandlung mit $\mathrm{Hg}$. damn eine günstige, wenn letzteres in den Harn übergeht. Jullien empfieblt die Einleitung der Hg. Behandlung, sobald die syphilit. Natur des Leidens festgestellt worden ist. Sofiantini verabreicht nur ganz minimale Dosen. Peterson meint, dass nicht nur Rauchen allein, sondern noch andere Irritantien denselben Effect auf die Dauer der Syphilis haben können.

\section{Freitag, 7. August. 4. Sitzungstag.}

Veiel (Canstatt). Ueber die Natur und die Bezielungen der Erythema exsudativum multiforme-Gruppe.

Ređ̄ner erklärt das Eryth. mult. Hebrae für eine selbständige, nicht contagiöse, vielleicht miasmatische Infectionskrankheit. Es tritt nanchmal epidemisch auf, gehört aber nicht zu den bösartigen Complicationen wie das Eryth. nodosum. Durch äussere Reize lässt sich dasselbe nicht hervorrufen; den von Kaposi erwälhten Fall, wo nach Ein. reibungen von grauer Salbe Eryth. mult. exsud. auftrat, vermag der Vortragende nicht dem Eryth. exsud. mult. Hebrae zuzurechnen. Ebenso wenig die Erytheme, welche Lew in nach Reizung ron Urethralerosionen beobachtet bat. Im Weiteren spricht sich $V$. dahin aus, dass das. Eryth. nodosum streng von Eryth. exsud. mult. Hebrae zu trennen ist. Es ist eine selbständige, zu schweren Complicationen führende Infectionskrankheit, die besonders bei mit Tuberculose hereditär belasteten und bei körperlich heruntergekommenen Individuen auftritt. Ganz entschieden. bestreitet V. den Zusammenhang von Eryth. exsud. mult. Hebrae mit Rheumatismus, während letzterer nach ihm bei Eryth, nodosum wirklich eine ätiologische Rolle zu spielen scheint. Indess nimmt $V$. an, dass das. Eryth, nodosum und der Rheumatismus arthriculorum acutus nicht iden- 
tisch, sondern nur mit einander verwandt seien. Streng zu trennen seien noch ferner vom Eryth. exsud. mult. Hebrae jene Erythemformen, welche im Verlaufe verschiedener Infectionskrankheiten - wie Cholera, Diphtherie, Typhas, Scharlach, Masern, Angina, Sepsis, Pyämie - auftreten. Diese sind wohl alle embolischer Natur und Folgen des Reizens der Bakterien, oder ihrer Toxine. Embolien ungiftiger Substanzen rufen keine Erytheme der Haut, sondern umschriebene weisse Flecken hervor, welche von einem schmalen, bläulichen, hämorrhagischen Rande umgeben sind.

Dr. Stephen Mackenzie (London). Ueber die Erythema multiforme-Gruppe.

Der Vortrag Mackenzies enthält eine Analysis von 167 Fällen, die er am "London Hospital" beobachtet hatte. Aus seinem Vortrag möchten wir zunächst hier hervorheben, dass die in Rede stehende Affection viel häufiger das weibliche als das männliche Geschlecht befällt. Nach der von M. entworfenen Statistik kommen auf 4 weibliche 1 männliches Individuum, und beim Erythema nodosum ist das Verhältniss des weiblichen zum männlichen Geschlecht 5 zu 1. Was das Alter anbelangt, so befand sich die Majorität der Patienten zwischen dem 10. und 30. Lebensjahre. Indess kommt die Krankheit bei Kindern unter zehn Jahren häufiger als bei Erwachsenen über 30 Jahren vor. Wenn je ein prädisponirendes Moment für die Erythema-Gruppen von Belang und Bedeutung ist, so wären es die verschiedenen rheumatischen Erkrankungen; so gelang es M. in $22 \%$, d. h. in 26 von 115 Erythema nodosum-Kranken mit Sicherheit einen vorhergegangenen acuten oder subacuten Gelenksrheumatismus nachzuweisen. Bei anderen Gelegenheiten hatte M. 108 Fälle von Erythema nodosum beschrieben und dabei gezeigt, dass bei 17 von diesen Kranken ein ausgesprochener articulärer Rheumatismus vorhergegangen ist. Rechnen wir also die letzteren Fälle, in denen nach M. der Rheumatismus als ein prädisponirtes Moment. vorhanden war, zu den ersteren hinzu, so ergibt sich, dass in 43 von 233 Erythemata nodosum-Fällen eine rheumatische Affection vorlag, d. $h$. mit anderen Worten in $19 \%$. Natürlich führt M. noch andere Fälle an, in denen vorhergegangene rheumatische Erkrankung angenommen werden könnte, aber nicht mit der in den vorhergehenden Fällen erwähnten. Sicherheit. Als andere prädisponirende Momente nennt M. noch: 1. Affectionen des Herzens - in 9 Fällen; 2. Gicht - in 2 Fällen; 3. Tuberculosis - in 2 Fällen; 4. Epilepsie - in 2 Fällen; 5. Hysterie I Fall; 6. Melancholie - $1 \mathrm{Fall}$; 7. uterine Erkrankungen - in 3 Fällen. 8. Kopfschmerz - 1 Fall; 9. acute Nephritis - 1 Fall und 10. in einem Fall liess sich der Ausbruch der Krankheit anf Unbilde des Wetters zurückführen. Beim Erythema multiforme scheint der Rheumatismus nicht. eine so grosse prädisponirende Rolle, wie beim Erythema nodosum zu spielen. Wiewohl Erythema fugax congestiver und nicht entzündlicher Natur ist, so würde es M. doch za der Gruppe der Erythemata rechnen aus dem Grunde, dass bei ihm, wie bei den anderen Erythema-Formen eine 
rheumatische Erkrankung vorherzugehen pflegt. Die Frequenz des Vorkommens von Rheumatismus bei Erythema multiforme würde der Vortragende auf $50 \%$ berechnen. Dass die verschiedenen Erythema-Erkrankungen gleich Rheumatismus mit besonderer Vorliebe das weibliche Geschlecht befallen und häufiger in der ersten Hälfte des Lebens vorkommen, dürfe viel für den ätiologischen Zusammenhang beider Affectionen sprechen. Die pathologisch-anatomischen Forschungen auf dem Gebiete der Erythemata-Gruppe liessen sich auf den Rheumatismus bis zu einem grossen Grade übertragen, dessen Pathogenese bis jetzt noch nicht klargelegt worden ist. Hier wie bei Rheumatismus würden wir die "materia morbi" in Form eines toxischen Agens im Blute zu suchen haben. Wie sich Mackenzies Fälle mit Bezug auf das Alter vertheilen, geht am besten aus der folgenden Statistik hervor:

Fâlle von Erythema.

\begin{tabular}{|c|c|c|c|c|c|c|c|}
\hline & $\int_{-\infty}^{\circ}$ & 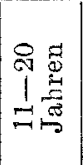 & 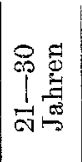 & $\underset{10}{P}$ & 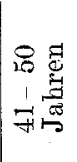 & 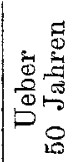 & 覃 \\
\hline \multirow{2}{*}{ Eryth. nodosum } & 4 & 11 & 1 & 0 & 1 & 0 & \multirow{2}{*}{$\left.{ }_{98}^{17}\right\} 115$} \\
\hline & 13 & 33 & 29 & 9 & 10 & 4 & \\
\hline \multirow{2}{*}{$\begin{array}{r}\text { Eryth. marginatum } \cdot . \mathrm{M} . \\
\mathrm{W} .\end{array}$} & 1 & 2 & 0 & 0 & 0 & 0 & \multirow{2}{*}{ 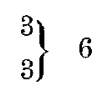 } \\
\hline & 0 & 3 & 0 & 0 & 0 & 0 & \\
\hline \multirow[t]{2}{*}{ Eryth. papulatum } & 0 & 0 & 1 & 1 & 0 & 0 & \multirow{2}{*}{$\left.\begin{array}{l}2 \\
3\end{array}\right\} 5$} \\
\hline & 0 & 1 & 0 & 1 & 0 & 1 & \\
\hline \multirow[t]{2}{*}{ Eryth. tuberculatrm . M. } & 0 & 3 & 0 & 0 & 0 & 0 & \multirow{2}{*}{$\left.\begin{array}{l}3 \\
0\end{array}\right\} \quad 3$} \\
\hline & 0 & 0 & 0 & 0 & 0 & 0 & \\
\hline \multirow[t]{2}{*}{ Eryth. multiforme } & 2 & 3 & 8 & 2 & 0 & 2 & \multirow{2}{*}{$\left.\begin{array}{l}12 \\
21\end{array}\right\} 33$} \\
\hline & 2 & 5 & 8 & 3 & 1 & 2 & \\
\hline \multirow[t]{2}{*}{ Eryth. fugax } & 0 & 0 & 2 & 0 & 0 & 0 & \multirow{2}{*}{$\left.\begin{array}{l}2 \\
3\end{array}\right\} 5$} \\
\hline & 0 & 0 & 1 & 1 & 1 & 0 & \\
\hline Total . . . . . . & 22 & 61 & 45 & 17 & 13 & 9 & 167 \\
\hline
\end{tabular}

G. Boeck (Christiania) tritt den Anschauungen von Stephen Mackenzie vollständig bei und möchte noch einen Schritt weiter gehen und die Purpura rheumatica in die Erythema-Gruppe einreichen. Für ihn sind Rheumatismus articulorum acutus, Eryth. mult., Eryth. nodosum, Herpes iris, Purpura rheumatica eine und dieselbe Krankheit; der Unterschied $z$ wischen denselben bestebt nur in der Verschiedenheit der Localisation 
der Affection und des Grades der Erkrankung. Die ätiologischen. Momente, soweit sie bis jetzt bekannt sind, sind bei den ebengenannten Affectionen dieselben und auch die Therapie, wenn sie von Erfolg begleitet sein soll. muss bei denselben die gleiche sein. In allen ebengenannten Affectionen wandte B. früher mit einem gewissen Erfolge das salicylsäure Natrium an, jetat und namentlich in schweren acuten Fällen, ging der Redner zur' Verabreichung von Antifibrin über, dessen energischere Wirkung als die des salicylsauren Natrium in den ebengenannten Erkrankungen er hervorhebt. Aber auch in den Fällen von Eryth. mult., wo kein Fieber besteht, ist die Wirkung des Antifibrins sebr schnell und auffallend. Dies beziehe sich, wie ausdrücklich von $B$. betont wird, auf die "ordinären Fälle" dieser Affection. Zurn Schlusse seiner interessanten Ausführungen meint noch B: „Es ist meine Ueberzeugung, dass die Auffassung dieser Affectionen als ein rheumatisches Leiden zum grossen Vortheil für unsere Patienten gereichen wird."

Prof. Janowski (Prag) meint, dass der Typas des Eryth. mult. Hebrae aufrecht erhalten und scharf von den übrigen Gruppen, besonders von Eryth: nodosum und Eryth. grave getrennt werden muss. Mit Eryth. nodosum können Combinationen vorkommen: der Typus Eryth. grave (Lewin) gehört nicht zum Eryth. mult. Es handelt sich dabei, wie J. durch bakteriologische Untersuchungen bewiesen hat, um eine Streptococcen-Invasion. Bei der Obduction konnten an Purpura Flecken, die während des Erythems entstanden waren, Streptococcen Embolien in den Capillaren nachgewiesen werden.

sabouraud (Paris). Ueber den Ursprung der Alopecie. (Sur l'origine de la Pelade.)

In diesem Vortrage gibt $\mathrm{S}$. die Resultate der Forschungen von 300 hierhergehörigen Patienten. Dieselbe lassen sich kurz wie folgt zusammenfassen.

I. Im Anfangsstadium der Krankheit lassen sich Mikroben - ein schmaler Bacillus $1 / 3 \mu$ breit und $1 / 2-1 \mu$ lang - nachweisen.

II. Wenn dieses Anfangsstadium vorüber ist, so lässt er sich nirgends, weder in der Haut noch in den Follikeln etc. finden.

Natali Amici (Rom). Aus Amici's Vortrag. "Sopra un methodo speciale di cura locale dell Erisipela" möchten wir Folgendes hervorheben. Bei dem Erysipel der Extremitäten finden sich bisweilen Zeichen einer latenten Infection, bestehend in Oedem und Schmerz auf digitalen Druck, bei ziemlicher Entfernung von dem eigentlichen Erkrankungsherde. Dieses Bild der latenten Infection lässt sich in zwei bis drei Tagen wegbringen, wenn Sublimat und Oel im Verbältniss von 1: 100 zweistündlich zur Application gelangt. Auf Grund klinischer Erfabrung behauptet A., dass Carbolsäure und Sublimat keineswegs durch das Hinzufügen von Oel ihre antiseptische Eigenschaften verlieren.

Perrin (Niarseilles). Traitement Surgical des Leucokératoses buccales. Bei 7 hierhergehörigen Patienten wandte P. mit grossem Frfolg den Galvano- resp. Thermo-Cauter an. Die Heilung blieb permanent. Zur Arehiv f. Dermatol. u. Syphil. Band XxxvII. 
Ausführung dieser einfachen Methode genügt eine locale Anästhesie. Heilung soll nach 3 bis 4 Wochen erfolgen.

G. Giarrochi (Rom) berichtet über eine Beobachtung von 550 Alopecie-Fällen. Er weist zunächst auf die Thatsache, dass die Erkrankung in Rom von Jahr zu Jahr zunehree und procentuarisch gerechnet, etwas um 5.23 alle anderen Hauterkrankungen übertrifft, hin. Die Krankheit hält G. für nicht contagiös, da er bis jetzt noch nicht eine epidemische Ausbreitung beobachtet hatte. In dem Entstehen der sogenannten Alopecie-Flecken scheint ein bestimmtes Gesetz zu walten, das sich in dem symmetrischen Auftreten derselben und in der Vorliebe bestimmter Körperregionen Nacken, Hinterkopf, temperale Gegend und die Wangen - zu befallen, sich äussert. Was den anatomischen Sitz dieser Alopecieläsionen anbelangt, so meint $G$., dass sie hauptsächlich in den Gegenden vorkommen, die vom Nervus trigeminus versorgt werden. G. hebt noch die interessante Beschreibung von A. C. Celsus in dem Abschnitte „De Areis" über diesen Gegenstand hervor.

Petrini de Galatz. Une nouvelle variété d'Acne. (Ame rubra Seborrhoica).

Bei zwei weiblichen Patienten im Alter von 30 resp. 35 Jahren beobachtete P. d. G. folgendes Bild. Bej der einen Patientin trat im Alter von 15 Jahren im Gesicht ein papulöser Ausschlag, der jeden Sommer verschwand, um im Winter wieder za erscheinen. Ohne wesentliche Aenderung hielt der ebengeschilderte Zustand 15 Jahre an, und erst im Winter dieses Jahres (1896) bedeckten sich diese papulösen Efflorescenzen mit starken Schuppen.

Bei der zweiten Patientin trat das gleiche Bild etwa zwei Jahre zurïck auf (1894), nur sind bei derselben die Schuppen reichlicher, etwa das ganze Gesicht einnehmend, dabei sind die Lippen geschwollen, verdickt und weisen einen desquamativen Process auf. Neben diesem papulösen Ausschlag bestehen noch kleine, von einem engen Saum umgebene Bläschen. Das ganze Bild würde zunächst an Lupus Eryth. oder ein trockenes, squamöses Ekzem denken lassen. Der weitere Verlauf jedoch zeigte, dass es sich um eine Acne-Form handelt, die bis jetzt noch nicht genügend studirt worden ist. Ichthyol in Form von Salben oder Kapseln wurde verabreicht, ebenso Schwefel-Pulver, und in beiden Fällen trat der gewünschte Erfolg ein.

P. G. Unna (Hamburg) trägt über Paraplaste, eine neue Form medicamentöser Pflaster, das unter U's. Anweisung von der Firma P. Beiersdorf \& Co. hergestellt ist, vor.

$$
\text { Freitag, 7. August. 4. Verhandlungstag. }
$$

\section{Section für Syphilis.}

Discussion über maligne Syphilis (Syphilis maligna).

A. Haslund (Kopenhagen). Die Syph. mal. gehört dem secundären und nicht dem tertiären Stadium an. Der Ausdruck "Syph. mal." ist: 
nicht glücklich, weil man gewöhnlich in der Medicin unter Malignität ganz andere Bedingungen und Erscheinungen versteht. Die Behandlung muss eine rein individaelle sein und sich nach der jeweiligen Schwere der Symptome und der Berücksichtigung des ganzen Krankheitsbildes richten. Die Affection ist im Ganzen selten; auf 8691 syph. Kranke, die während der letzten 14 Jahre in dem Kopenhagener Municipal-Hospital behandelt worden sind, kamen 39 s. m. Fälle vor. Die Prognose ist relativ gut.

Prof. Tanovsky (Petersburg) hält eine Misch-Infection - Staph. pyog. aureus und albus, bisweilen auch unter Mitwirkung einer besonderen Form von Bacillen - als Grundbedingung für das Zustandekommen der Syph. mal. Demnach sind die Haut-Eruptionen dieser Affection pyosyphilitischer Natur. $Z a$ den pyo-syphilitischen Formen zählt eben T. Ecthyma profundum rupiaeforme, impetigo profunda, rodens, rupia, Syphilide-pustulo-crustacée etc. Diese eben beschriebenen Charaktere der S. m. treten zu gleicher Zeit mit den anderen secundären Symptomen der S. auf. Dabei besteht zugleich als besonderes Characteristicum der Mischinfection eine purulente Entzündung der in der Gegend der Initial-Sclerose gelegenen Drüsen. Freilich hängt noch der weitere Grad der Malignität der Syphil. von der Ausdehnung und Multiplicität der Erscheinungen ab. Sehr selten in dem tertiären, meistens im secundären Stadium wird die S. $m$. beobachtet.

Prof. Neisser (Breslau) versteht unter Syph. maligna eine qualitativ eigenartige Form bösartiger Syphilis, während er mit Syph. gravis jede durch die Localisation der Syph. in lebenswichtigen Organen oder durch etwaige Complicationen mit anderen Dyscrasien und Krankheiten gefahrbringende, eventuell tödtliche syphilitische Erkrankung bezeichnet. Die Bezeichnung "Syphilis anomale grave" bedeutet die Verschiebung der ulcerösen Formen in die Frühperiode. Die S. m., die jetzt eine seltene Krankheitsform ist, ist charakterisirt: durch ihre hochgradigen, von der Intoxication herstammenden Allgemeinerscheinungen; dahin gehören: Fieber, Anämie, Cachexie; Abmagerung, Schlafosigkeit, Kopf-, Gelenk-, Muskel-Schmerzen, und was allerdings selten der Fall ist, epileptiforme Anfälle, Coma, vorübergehende Bewegungs- und CoordinationsStörungen; durch ihr frühes Auftreten, nämlich 3 bis 6 Monate nach der Infection; durch ibre Neigung zu Recidiven; durch ihre zahlreiche, unregelmässige, gross-pustulöse Form und Ulcerationen (Rupia- oder Eethyma-Formen).

Die hämorrhagischen Formen gehören an sich nicht zum Bilde der Malignität; sie können aber die letzteren compliciren und so als ein Symptom derselben auftreten. In demselben Sinne ist auch Scorbut aufzufassen, wenn er zu einer bereits vorhandenen Syph. sich hinzugeselit. Die Syph. mal. ist sowohl durch ibre Multiplicität und reichliche Vertheilung der Eruption, wie durch die Zeit ibres Auftretens als. eine Frühform aufzufassen. Von den maculösen und papulösen Frühformen 
unterscheidet sie sich wesentlich durch den Zerfall des Ulcerationsvorganges.

Von der tertiär-gummösen Form, mit der sie hinsichtlich ihrer ulcerativen Vorgänge Aehnlichkeit hat, unterscheidet sie sich: durch die ungemein schnelle Entwicklung des Ulcerations-Processes; Abwesenheit eines serpiginösen Charakters; durch den Mangel der vielen Spätformen; durch die ganz unregelmässige Wirkung der Jodsalze auf diesen Process.

Gegen die Auffassung der S. m. als einer tertiären Form sprechen die folgenden Punkte:

1. Das. gleichzeitige Bestehen von Eruptionen, die den Frühformen angehören, neben Rupia und Ecthyema der Haut.

2. Die Thatsache, dass den ulcerösen Eruptionen bisweilen typische, maculöse und papulöse Ausschläge nachfolgen können.

N. bezeichnet den Ausdruck "gallopirende Syphilis" und "Syphilis maligne précoce" als unpassend. Auch bekämpft $\mathrm{N}$. die Neigung mancher Syphilidologen, alle visceralen Formen der Syphilis als tertiäre Erscheinungen hinzustellen. Das hat zur Folge, dass die Quectsilber-Behandlung vernachlässigt wird, dass das nur für das tertiäre Stadium bestimmte Jodkalium allein zur Anwendung gelangt, wodurch bei der visceralen, wie cerebralen Syphilis - da sie secundären Ursprunges sind - das Krankheitsbild verschleppt wird. Die S. m. wiederum kann sowohl acquirirt, wie hereditär sein. Speciell kann man die bei schwerer hereditärer Syph. vorhandenen Erscheinungs- und Vereiterungs-Processe der malignen Form zurechnen. Bei der Entwicklung des ulcerösen Gewebszerfalles ist Misch-Infection (Staphylococeen) vorhanden. Sie ist aber nicht nach $\mathrm{N}$. die Ursache, sondern viel mehr eine Complication des Ulcerations-Processes. Die Hypothese, wonach eine reichliche Quantität von Syphilis-Virus die Ursache der Malignität sei, hat gar keine Unterlage. Auf die Frage übergehend, warum seit den letzten 400 Jahren die $\$$. m. immer seltener sich zeigt, meint $N$., dass dies zur Zeit nicht mit Bestimmtheit beantwortet werden könne. Ws lässt sich wohl denken, dass die Resistenz gegen das Virus im Allgemeinen grösser und zugleich die Bösartigkeit des Virus abgenommen habe. Auch N. bestätigt die Erfahrung, dass Quecksilber von Kranken mit Syph. mal. häufig schlecht oder gar nicht vertragen werde. Er hält es nicht für nothwendig, die Quecksilber Therapie bei dieser Form ganz zu streichen, sondern empfieblt im Anfang der Behandlung mit Hg. mit grosser Vorsicht zu verwenden und verwirft die sogenannten forcirten Curen. Der Primäraffect in Bezug auf seinen Sitz, Verlauf und sonstige Beschaffenheit hat mit der Entstehung der S. ra. nichts zu thun. Die Prognose, meint N. gleich $\mathrm{H}_{\mathrm{a}} \mathrm{sl}$ und, ist im Allgemeinen gut.

Magnus Möller nimmt in der Syph. mal. eine secundäre Mischinfection an. Er berichtet über seine hierher gehörigen Untersuchungen in folgender Weise: Inoculation, mikroskopische Untersuchung, Culturversuche mit dem Inhalte von jungen zwei bis drei Tage alten Pusteln erwitesen sie 
als bakterienfrei; wurde dagegen der Inhalt von älteren Effiorescenzen, in denen bereits nekrotische Zerstörungen deutlich waren, untersucht, so liessen sich darin constant Staphylococcen und Streptococeen nachweisen. Daher stellt M. den folgenden Satz auf: Das syphilitische Virus selbst ruft die pustulösen Efforeseenzen hervor, später, secundär, kommt auch eine Miscbinfection hinzu.

Brandis nimmt ebenfalls auf Grund seiner hierhergehörigen Erfahrungen eine Misch-Infection an.

Güntz (Dresden). Syph. mal., meint G., heilt meistentheils und fügt noch hinzu, dass wir nicht im Stande sind, eine allgemeine, pathologische, anatomische Definition zu geben, weil wir unter S. m. solche Störungen verstehen, welchen ganz verschiedene Ursachen - z. B. Tuberculose, Diabetes, Carcinom, Diathesis, Intermittens, Rbeumatismus, Einfluss der Tropen, Anämie (perniciosa und simplex) etc. etc. etc. - zu Grunde liegen. Mit Rücksicht darauf, meint noch G., dass die Behandlung nicht in allen Fällen dieselbe sein kann. Deshalb solle in Fällen schwerer syphilitischer Formen, in denen das Quecksilber erfahrungsgemäss nicht angewendet werden darf, ein anderes Mittel, z. B. das Kalium Jodatum, in Anwendung gezogen werden.

Fitz Gibbon (Dublin) versteht unter "Malignant Syphilis" eine Krankheitsform, die sich von der gewöhnlichen dadurch abhebt, dass noch septische Processe zu ihr hinzutreten. Inoculation mit dem Inhalte eines gangränösen, phagedänischen oder eiternden Chancres würde die septische Form dieser Krankheit zustande bringen, während die Ueberimpfung von gewöhnlichem Virus nur die milde Form hervorbringen wird.

Arning (Hamburg) meint, es sei auffallend, dass die alte Luehre von der schlechten Wirkung des Mercurs in den Anfangsstadien der Syph. mal. gelegentlich dieser Discussion Angriffe erfahren hat. A. hatte im vorigen Jahre Gelegenheit gehabt, sich zu überzeugen, dass das Quecksilber in manchen Fällen, local und allgemein, gradezu schädlich wirken kann. In einem Falle, einen 35jährigen Mann betreffend, der mit einem phagedänischen Ulcus in A's. Behandlung kam und bald darauf zahlreiche andere phagedänische Ulcerationen an anderen Körperstellen zeigte, war die Verabreichung von Quecksilber von Fieber begleitet, und erst nach $3 / 4$ Jahren konnte der Patient Quecksilber vertragen. Zur Reinigung der Geschwüre erwies sich in diesen Fällen eine 10\% Lösung von Wasserstoff-Superoxyd am zweckmässigsten.

Prof. Schwimmer (Budapest) spricht sich auf Grund seiner Erfahrungen dahin aus, dass das Quecksilber bei Syph. mal. den Krankheitszustand entschieden exschwere. Die Berücksichtigung der Verbältnisse des gesammten Organismus ist bei der Syph. mal. eine Haupt-Indication, daher wendet S. Chinin und Eisen an und empfiehlt zu weiteren Versuchen die organische Therapie. Ueber die Prognose lässt sich kein einheitlichs Gesetz. aufstellen. 
Drystale (London). In unserer Zeit kommt Syph. mal. selten vor, vielleicht Einer auf 200 Fälle. Bei Syph. mal. und speciell in ibren confluirenden Formen ist der krankhafte Verlauf an keine Gesetze und Perioden gebunden. Wann die S. m. zum Ausbruch gelangt, lässt sich nicht mit Sicherheit festsetzen. Es sind Fälle bekannt, wo sie bereits wenige Monate nach Erscheinen des Primäraffectes sich zeigte; es bildet sich dann ein ausserordentlich schweres Krankheitsbild aus, auf das selbst die sorgfältigste Behandlung keinen Einfiuss erlangt. $\mathrm{Zu}$ den anderen. Symptomen, Tie die S. m. begleiten, rechnet D. Albuminurie und ausgedehnte Ulcerationen, die, wie er an seinem bier mitgetheilten Patienten (bei einem Falle mit Prof. Boeck aus Christiania beobahtet) demonstrirt, die ganze Hantfläche des Körpers einnahmen. In S. m., meint D., ist die Anwendung von Mercur contraindicirt, dagegen ist Jod-Kalium in grösseren Dosen am Platze.

Loewenhardt theilt mit, dass er mehrere Fälle von acuter ulcerativer Syphilis beobachtete, bei welchen die Prognose schlecht zu sein schien, doch gingen die schweren Erscheinungen auf Anwendung einer Salbe von $\mathrm{Hg}$ oxyd. flav. in Heilung über.

Feulard (Paris) schreibt den Serum-Injectionen eine toxische Wirkung zu und hält für das Zustandekommen des Krankheitsbildes "Syph. mal." eine Mischinfection für nothwendig.

Audry (Toulouse). Gleich Feulard billigt A. die von Prof. Schwimmer empfohlene Behandlungsmethode der S. m.

Jullien (Paris). Note sur l'ulceration blennorrhagique. Aus dem interessanten Vortrage Jullien's möchten wir hervorheben, dass die mikroskopische Untersuchung des Inhaltes dieser Affection die Anwesenheit von zahlreichen Mikrococcen, Staphylococcen und in manchen Fällen von Gonococcen ergeben hat.

Prof. Janovski (Prag) bemerkt in der Discussion zu diesem Vortrage Folgendes: Bei Männern findet man ebenso Ulcerationen: 1. bei peri-folliculären Infiltrationen, 2. nach lang fortgesetztem Gebrauch von starken Argentum-Nitricum-Lösungen; manchmal bei Urethr. granulosa circumscripta bei Weibern.

Freitag 7. August, Nachmittagssitzung (im grossen Auditorium).

Lassar (Berlin) demonstrirt eine elektrische Lampe zur Beleuchtung der Vaginalspecula. An derselben ist noch eine weitere Vorrichtung angebracht, die zur Vergrösserung dient. Prof. Lassar zeigt noch u. A. eine Reihe Leprafälle, ferner Abbildungen von Psoriasis, Lues etc. etc. vor, die in Bezug auf Naturtreue in Wiedergabe der Farben nichts zu wünschen übrig lassen.

Justus (Budapest). Ueber Blatveränderung durch Syphilis. Unbehandelte Syph. vermindert den Hämogl-Gehalt des Blutes. Wixd ein syphilitischer Patient einer Cur unterworfen, so sinkt 
bei der ersten Einreibung oder bei der ersten intramusculären oder intravenösen Injection der Hämogl.-Gehalt des Blutes ganz bedeutend, um bei fortgesetzter Behandlung allmälig wieder in die Höhe zu gehen. Der charakteristische Abfall bei Beginn der Hg.-Cur ist bei allen Formen (secundär, tertiär) der Syphilis zu beobachten, nur bei Primär-Affectionen, die noch keine Schwellung der Drüsen nach sich zugen, wurde er vermisst. Bei Gesunden oder anderweitigen Kranken bewirkt Hg. kein Sinken des Hämoglobin-Gehaltes. Dieser Umstand, meint J., könnte diagnostisch verwerthet werden.

Feibes (Aachen). Zur Diagnose der extragenitalen Syphilis - Infection. F. gibt eine Statistik von 45 Fällen, an der Hand deren er die folgenden Punkte zu illustriren sucht. Die Prognose dieser Form ist nicht schlechter, wie die der genitalen Syphilis. Das Gleiche gilt von dem Vorkommen tertiärer Erscheinungen und Recidive, die nicht häufiger sind, wie bei der genitalen Infection.

Loewenhardt spricht sich ebenfalls dabin aus, dass die Prognose bei der extra-genitalen, wie genitalen Syphilis die gleiche ist. Auffallend ist allerdings die kolossale Drüsen-Induration.

Drysdale beobachtete mehrere Fälle extra-genitaler Syphilis. Der Verlauf und die weiteren Symptome derselben scheinen wenig Abweichungen von der genitalen Syphilis zu zeigen.

Grünfeldt (Wien). In Bezug auf die extra-genitalen Fälle von Syph.Infection ist das Auftreten intensiver Erscheinungen gewiss zu bestätigen. Solche werden an verschiedenen Körperstellen beobachtet. G. erwälnt einen Fall von Sclerose der Tonsilen, in dem nicht nur die localen Beschwerden gross waren, sonders auch heftiger einseitiger Kopfschmerz bedeutender als in gewöhnlichen Syphilis-Fällen zugegen war.

Bertarelli (Mailand), Soffianti (Pavia), Balzer (Paris) stellen die extra-genitale Infection mit Bezug auf Prognose und Schwere der Erscheinungen der genitalen gleich. Der letztere Redner (Balzer) verweist auf die von F'ournier in la "Medecine Moderne" 1895 veröffentlichte Statistik extra-genitaler Infection. Er selber allerdings beobachtete, dass in zwei Fällen von Lippen-Chancre das Bild der sogenannten Syph. mal. sich entwickelte.

S.amstag, 8. August. 5. Sitzungstag.

A. Blaschko (Berlin). Ueber Lepra in Deutschland.

Von Livland und Curland wurde die Lepra durch Menschenverkehr in Preussen eingeschleppt. Speciell ist der Kreis Memel von dieser Seuche heimgesucht worden, die daselbst seit 15 oder 20 Jahren anhält. Die Ausbreitungsweise der Lepra spricht für ihren contagiösen Charakter und gegen die Annahme einer autochthonen Entstehung. Nur Isolation allein, meint B., vermag die weitere Ausdebnung der Lepra in Deutschland zurückzuhalten resp. zu verhindern. Dass die Krankheit im Ganzen nicht so rapiden Fortschritt nehme, hängt erstlich von der IImmunität der meisten Menschen gegen die Lepra-Erkrankung und von der biologischen 
Natur der Bacillen - sie verlassen nur selten den inficirten Organismus - ab. Die Leprabacillen befinden sich nach $B$. innerhalb der Zellen. Die Syringomyelie und die sogenannte Lepra anaesthetica sind in ätiologischer wie pathologischer Beziehung zwei grundverschiedene Krankheiten; bei der ersteren ist immer und primär das Räckenmark ergriffen, bei der letzteren selten und dann auch nur secundär.

v. Petersen (St. Petersburg). Die Verbreitung der Lepra in Russland.

P. befürwortet energisch die Isolirung der Lepra-Kranken, was nur durch Einrichtung von Asylen oder Stiftung von Colonien zu erreichen ist. Derartige Einrichtungen, nämlich 5 Asyle und 2 Colonien bestehen bereits in Russland und man ist nun dabei, ihre Zahl zu vermehren. Die Zahl der zu errichtenden Asyle, resp. Colonien wärde sich natürlich nach dex Zahl der vorhandenen Lepra-Fälle richten, und um letztere zu eruiren, hat die kaiserliche russische Regierung im Juli 1895 durch Erlass eingeführt, dass jeder Lepra-Fall polizeilich angemeldet werden soll. Diese Vornahme ergab nach einem Jahre -- Juli 1896 -- die Zahl von wirklichen Lepra-Kranken in der Höhe von 894 und den grössten Procentsatz, $63.3 \%$, bildete darunter die sogenannte Lepra nodosa.

Was das Alter der Leprösen betrifft, so befanden sich unter 5 Jahren. $3 \%$, von da bis zu 20 Jahren $14.42 \%$, über 50 Jahre $28.2 \%$ und über 70 Jahre $4.1 \%$. In 18 Fällen wurde die Lepra von einem Gatten auf den anderen ühertragen. Dies meint P., spricht doch gewiss für den contagiösen Charakter der Lepra. In allen Ländern sollte die Anmeldepflicht und das Asyl- resp. Colonie-System eingefübrt werden.

Neisser (Breslan) vertritt mit aller Energie die Auffassung, dass die Lepra contagiös sei. Die Bacillen sind zweifellos die einzige Ursacle der Erkrankung. Dieselbe kann nur entstehen, wem die Bacillen auf irgend eine Weise in den Organismus eindringen. Daraus folgt noch nicht, dass jeder Lepröse seine Umgebung anstecken muss, weil Disposition und andere Momente zugegen sein müssen. Die Verbreitung der Bacillen geht von den Krankheitsherden der Haut, Mund und Nasenhöhle aus. Die chirurgische Behandlung Campana hält $N$. für überflüssig. Es genügen verschiedene antiseptische Maassnahmen, um die oberflächliche Leprose zu beseitigen, resp. geschlossen zu erhalten.

Campana (Rom). Lepra; Vorschläge zur Verminderung der Ausbreitung dieser Krankheit. C. weist zunächst auf die Nothwendigkeit einer internationalen Verständigung in Bezug auf die Behandlung der Lepra hin. Die locale Behandlung der Lepra kommt namentlich in ihren ersten Stadien in Betracht. Sie sei eine radicale, chirurgische, verbunden mit nachfolgender Cauterisation. Im Verlaufe der Lepra können sich hohes Fieber und andere schwere Erscheinungen geltend machen; dies ist der Ausdruck eines septischen Processes, der, durch den Ulcerationsprocess bedingt, das Krankheitsbild complicirt und die allgemein übliche Behandlung erfordert. 
Feibes (Aachen). Ueber eine längere Zeit hindurch fortgesetzte Mercur-Behandlung.

Idiosyncrasie gegen Mercur kommt allerdings vor; ist aber im Ganzen genommen ausserordentlich selten. Dasselbe gilt von der sogenannten mercuriellen Polyneuritis. Welches sind die Grundbedingungen, um für längere Zeit eine Mercur-Behandlung fortsetzen zu dürfen? Lungen und Nieren müssen sich in einem normalen Zustande befinden, es ist ferner rathsam, das Körper-Gewicht des Patienten, etwa zweimal wöchentlich, zu controliren. Gewichtsverlust würde eine Contraindication gegen die Fortsetzung der Behandlung abgeben. Blutuntersuclungen müssen von Zeit zu Zeit ausgeführt werden. Eine Alteration der Blutbestandtheile würde die weitere Mercur-Behandlung contraindiciren. Auch bei den syphilitischen Augen-Affectionen hat sich die lange Zeit fortgesetzte Mercur-Behandlungen vortheilhaft erwiesen (Alexander). Von Gehirn-Affectionen würden Meningitis and Meningo-Encephalitis F. hat einen hierhergehörigen Fall durch 3 Monate fortgesetzte MercurVerabreichung erfolgreich behandelt - für diese Behandlung in Betracht kommen. Auch für die sogenannte Erb'sche syphilitische Spinal-Paralysis empfiehlt sich diese Behandlungs-Methode. Mercur-Einreibungen eignen sich am besten für diese Medication. 